OPEN ACCESS

Edited by:

Yuan Shen,

Tongji University, China

Reviewed by:

Jiaqiang Zhang,

Zhengzhou University, China

Feng Liang,

Massachusetts General Hospital,

United States

Mian Peng,

Wuhan University, China

*Correspondence:

Hui Zheng

zhenghui0715@hotmail.com

Received: 10 February 2020

Accepted: 16 June 2020

Published: 18 August 2020

Citation:

Ni C, Qian M, Geng J, Qu Y, Tian Y, Yang N, Li S and Zheng H (2020) DNA Methylation Manipulation

of Memory Genes Is Involved in Sevoflurane Induced Cognitive

Impairments in Aged Rats.

Front. Aging Neurosci. 12:211.

doi: 10.3389/fnagi.2020.00211

\section{DNA Methylation Manipulation of Memory Genes Is Involved in Sevoflurane Induced Cognitive Impairments in Aged Rats}

\author{
Cheng Ni ${ }^{1}$, Min Qian ${ }^{2}$, Jiao Geng ${ }^{1}$, Yinyin $\mathrm{Qu}^{2}$, Yi Tian ${ }^{1}$, Ning Yang ${ }^{2}$, Shuai $\mathrm{Li}^{1}$ and \\ Hui Zheng ${ }^{1 *}$ \\ ' Department of Anesthesiology, National Cancer Center/National Clinical Research Center for Cancer/Cancer Hospital, \\ Chinese Academy of Medical Sciences and Peking Union Medical College, Beijing, China, ${ }^{2}$ Department of Anesthesiology, \\ Peking University Third Hospital, Beijing, China
}

DNA methylation is an essential epigenetic mechanism involving in gene transcription modulation. An age-related increase in promoter methylation has been observed for neuronal activity and memory genes, and participates in neurological disorders. However, the position and precise mechanism of DNA methylation for memory gene modulation in anesthesia related cognitive impairment remained to be determined. Here, we studied the effects of sevoflurane anesthesia on the transcription of memory genes in the aged rat hippocampus. Then, we investigated changes in DNA methylation of involved genes and verified whether dysregulated DNA methylation would contribute to anesthesia induced cognitive impairment. The results indicated that sevoflurane anesthesia down-regulated the mRNA and protein levels of three memory genes, Arc, Bdnf, and Reln, which were accompanied with promoter hypermethylation and increased Dnmt1, Dnmt3a, and Mecp2 expression, and finally impaired hippocampus dependent memory. Furthermore, inhibition of DNA hypermethylation by 5-Aza rescued sevoflurane induced memory gene expression decrease and cognitive impairment. These findings provide an epigenetic understanding for the pathophysiology of cognitive impairment induced by general anesthesia in aged brain.

\section{Keywords: DNA methylation, epigenetic, anesthesia, memory gene, cognitive impairment}

\section{INTRODUCTION}

A progressive loss of cognitive function characterized by impairments in memory is common in aging and creates a context favorable for the development of neurodegenerative diseases such as Alzheimer's disease (AD) (Barter and Foster, 2018). However, the rate and severity of cognitive aging vary widely across the elderly. Recently, epigenetic modification emerges as a crucial mechanism in shaping phenotypic differences of cognitive aging through gene-environment interactions (Barter and Foster, 2018). DNA methylation, one of the most extensively investigated epigenetic mechanisms, is an essential mediator of memory associated gene transcription, typically resulting in transcriptional silencing and loss of gene function. DNA methylation is catalyzed by DNA methyltransferases (DNMTs), including DNMT1, DNMT3a and 3b. These enzymes transfer a methyl group from S-adenosylmethionine (SAM) to a cytosine, and most commonly occurs 
at cytosines followed by a guanine residue, referred to as $\mathrm{CpG}$ sites of DNA promoter regions (Okano et al., 1999). An agerelated increase in promoter methylation has been observed for neuronal activity and memory genes and is involved in neurological disorders (Delgado-Morales et al., 2017). Affected genes implicated in learning and memory notably include the brain derived neurotrophic factor (Bdnf) (Lubin et al., 2008), activity-regulated cytoskeletal-associated protein (Arc) (Epstein and Finkbeiner, 2018), early growth response 1 (Egr1, also known as Zif268) (Sun et al., 2019), Reln (Stranahan et al., 2013; Pujadas et al., 2014) and Ppp3ca (also known as calcineurin) (Miller et al., 2010).

Approximately $30 \%$ of the population aged 65 years or more are exposed to some form of anesthesia annually (Evered et al., 2017). Aging induced neural degenerative changes predispose them to a higher incidence of perioperative neurocognitive disorders (PNCD), including postoperative cognitive dysfunction (POCD) (Moller et al., 1998; Monk et al., 2008; Evered et al., 2018). Although the causes of POCD are complicated and remain to be elucidated, inhaled anesthetics are now being recognized as a potentially significant risk to cognitive performance at extreme age (Jevtovic-Todorovic et al., 2013; Schulte et al., 2018). Our studies and others revealed that exposure to inhaled anesthetics could result in synaptic and cognitive dysfunction (Ni et al., 2015, 2017). Recent work has begun to investigate anesthesia triggered epigenetic modifications within the neonatal rats (Chastain-Potts et al., 2019). However, the manipulation of DNA methylation and its precise mechanism for memory genes in the aged hippocampus and their relationships with anesthesia related cognitive variation remained to be determined. In the present study, we tested whether sevoflurane, one of the most commonly used inhaled anesthetics for general anesthesia, would suppress the transcription of memory genes in the hippocampus of aged rats. Then, we investigated changes in the profile of DNA methylation of involved genes and verify whether dysregulated DNA methylation within hippocampus would contribute to anesthesia induced cognitive impairment. We aim to elucidate the epigenetic mechanisms underlying neurocognitive disorders induced by anesthesia in the aged brain.

\section{MATERIALS AND METHODS}

\section{Animals and Anesthesia}

Male Sprague-Dawley rats, 18-month old, weighing 550-600 g, were used in the studies. Before sevoflurane anesthesia, the rats were maintained on a standard housing condition with food and water ad libitum for 2 weeks. The animal experiments were performed in accordance with the guide for the care and use of laboratory animals and the protocol was approved by the local biomedical ethics committee (No. LA2018085).

Minimum alveolar concentration (MAC) of sevoflurane for rats has been reported as 2.4 2.7\% (Li et al., 2014). In our study, rats were randomly assigned to control or sevoflurane group. The rats in anesthesia group received $2.5 \%$ sevoflurane in $100 \%$ oxygen for $4 \mathrm{~h}$ in an anesthetizing chamber, while the control group received $100 \%$ oxygen at an identical flow rate for $4 \mathrm{~h}$ in an identical chamber. The rats breathed spontaneously, and sevoflurane and oxygen concentrations were monitored continuously (Datex, Tewksbury, MA, United States). The temperature of the anesthetizing chamber was controlled to maintain the rectal temperature of rats at $37 \pm 0.5^{\circ} \mathrm{C}$. This anesthesia protocol has been shown not to significantly alter values of blood pressure and blood gas in the preliminary studies. Anesthesia was terminated by discontinuing sevoflurane and placing animals in a chamber containing $100 \%$ oxygen until 20 minutes after the recovery of consciousness. The animals were then returned to individual home cages until sacrifice. Rats were sacrificed by decapitation $3 \mathrm{~h}$ after anesthesia. The brain tissues were removed rapidly, and the hippocampus was dissected out and frozen in liquid nitrogen.

\section{Cell Culture and Treatments}

C6 rat glioma cells were used in the studies. The cells were cultured in F-12K medium (Gibco ${ }^{\mathrm{TM}}$, Thermo Fisher Scientific, Waltham, MA, United States) containing 2.5\% fetal bovine serum, $15 \%$ horse serum, $100 \mathrm{U} / \mathrm{ml}$ penicillin, and $100 \mu \mathrm{g} / \mathrm{ml}$ streptomycin. Before treatments, cells were seeded in 6-well plates, with one million cells in $1.5 \mathrm{ml}$ cell culture media per well, as described in our previous studies (Ni et al., 2017). The cells were randomly assigned to a treatment or control group. In treatment group, the cells were treated in a sealed plastic box in a $37^{\circ} \mathrm{C}$ incubator, with $4.1 \%$ sevoflurane, plus $21 \% \mathrm{O} 2$ and $5 \%$ $\mathrm{CO} 2$, delivered from an anesthesia machine for $4 \mathrm{~h}$ as described previously (Dong et al., 2009). The cells in the control group received vehicle gas in the same condition. A Datex infrared gas analyzer (Puritan-Bennett, Tewksbury, MA, United States) was used to continuously monitor the delivered concentrations of carbon dioxide, oxygen and sevoflurane. Then the treated cells were harvested and frozen in liquid nitrogen.

\section{DNA Methylation Modulation}

To conduct the in vivo induction of DNA hypomethylation, rats were randomly assigned to control, 5-Aza- $2^{\prime}$-deoxycytidine (5Aza), sevoflurane or sevoflurane +5-Aza group. 5-Aza (Abcam, Cambridge, United Kingdom) is a DNMT1 activity inhibitor and could induce DNA hypomethylation (Christman, 2002). It was dissolved in sterile water and injected intraperitoneally $30 \mathrm{~min}$ before anesthesia with $0.5 \mathrm{mg} / \mathrm{kg}$ dosage chosen based on the preliminary study and a previous study (Williams-Karnesky et al., 2013). The control and sevoflurane groups received a vehicle injection (sterile water).

For the in vitro induction of DNA hypomethylation, the cells were randomly assigned to control, 5-Aza, sevoflurane or sevoflurane +5-Aza group. 5-Aza was given $60 \mathrm{~min}$ before sevoflurane treatment in 5-Aza or sevoflurane +5-Aza group, and the concentration was $10 \mu \mathrm{M}$ based on a previous study (Tan et al., 2017). For the in vitro induction of DNA hypermethylation, the cells were randomly assigned to control, S(5-Adenosyl)-L-methionine disulfate tosylate (SAM), sevoflurane or sevoflurane + SAM group. SAM (Methyl donor, Abcam, Cambridge, United Kingdom) was also given $60 \mathrm{~min}$ before sevoflurane treatment in SAM or sevoflurane + SAM group, 
and the concentration was $100 \mu \mathrm{M}$ based on a previous study (Maddocks et al., 2016).

\section{RNA Extraction and Quantification}

Total RNAs were isolated from the hippocampi and cells using TRIzol reagent (Invitrogen, Carlsbad, CA, United States), then were digested with RNase-Free DNase to remove residual DNAs. The RNA concentrations were analyzed using the Nanodrop 2000 (Thermo Fisher Scientific), then total RNA ( $2 \mu \mathrm{g})$ was reverse-transcribed using the GoScriptTM Reverse Transcription System (Promega).

\section{Quantitative Real-Time PCR (qPCR)}

Quantitative real-time PCR was performed on CFX96 Real-Time PCR Detection System (Bio-Rad, Hercules, CA, United States). Amplification mixture consisted of PowerUpTM SYBR ${ }^{\circledR}$ Green master mix (Thermo Fisher Scientific), $10 \mu \mathrm{M}$ forward and reverse primers (Invitrogen, Carlsbad, CA, United States) and approximately $1.5 \mu \mathrm{l}$ of cDNA template. Primer sequences were obtained from the literature and checked for their specificity through in silico PCR. The forward and reverse primers are shown in Table 1. Amplification was carried out with an initial denaturation step at $95^{\circ} \mathrm{C}$ for 2 min followed by 45 cycles of $95^{\circ} \mathrm{C}$ for $10 \mathrm{~s}, 55^{\circ} \mathrm{C}$ for $30 \mathrm{~s}$ and $60^{\circ} \mathrm{C}$ for $30 \mathrm{~s}$, then $65^{\circ} \mathrm{C}$ for $2 \mathrm{~min}$ in $10 \mu \mathrm{l}$ reaction volume. All reactions were run in duplicate and the results were averaged from 6 independent studies. qPCR was quantified in two steps. First, $\beta$-actin levels were used to normalize target gene levels ( $\Delta$ Cycle threshold $(\Delta \mathrm{Ct})=\mathrm{Ct}_{\text {target gene }}-\mathrm{Ct}_{\beta \text {-actin }}$, target gene level $\left.=2-\Delta \mathrm{Ct}\right)$. Second, the target gene levels of sevoflurane group were presented as the percentage of those of control group, and 100\% of the target gene levels referred to the control levels.

TABLE 1 | The primer sequences used for qPCR.

\begin{tabular}{|c|c|c|}
\hline Genes & Orientation & Sequence $\left(5^{\prime}\right.$ to $\left.3^{\prime}\right)$ \\
\hline \multirow[t]{2}{*}{$\operatorname{Arc}$} & Forward & CTCCAGGGTCTCCCTAGTCC \\
\hline & Reverse & TGAGACCAGTTCCACTGCTG \\
\hline \multirow[t]{2}{*}{ Bndf } & Forward & GTGACARTATTAGCGAGTGGG \\
\hline & Reverse & GGGTAGTTCGGCATTGC \\
\hline \multirow[t]{2}{*}{ Reln } & Forward & AAACTACAGCGGGTGGAACC \\
\hline & Reverse & ATTTGAGGCATGACGGACCTATAT \\
\hline \multirow[t]{2}{*}{ Egr1 } & Forward & ACGCCATATAAGGAGCAGGA \\
\hline & Reverse & TATTGGAACAGCAGCAGTGG \\
\hline \multirow[t]{2}{*}{ Рpp3ca } & Forward & TGAACATAGCCAGGGTCACA \\
\hline & Reverse & GAAGGCGACGAGTAAACAGC \\
\hline \multirow[t]{2}{*}{ Dnmt1 } & Forward & AAATCCGTCTGTGGAAGGTG \\
\hline & Reverse & GCGGTAGAAAAGCCAATGAG \\
\hline \multirow[t]{2}{*}{ Dnmt3a } & Forward & TGTGAATGATAAGCTGGAGTTGC \\
\hline & Reverse & GGTGGTAATGGTCCTCACTTTG \\
\hline \multirow[t]{2}{*}{ Dnmt3b } & Forward & GAATTTAGCAGCCCAGGTTG \\
\hline & Reverse & AAGAAGAGCCTTCCTGTGCC \\
\hline \multirow[t]{2}{*}{ Mecp2 } & Forward & GGTAGAAAGCCTGGGAGTGT \\
\hline & Reverse & TTCTTGATGGGGAGCACAGT \\
\hline \multirow[t]{2}{*}{ Actb } & Forward & AGAGCTATGAGCTGCCTGA \\
\hline & Reverse & AATTGAATGTAGTTCATGGATG \\
\hline
\end{tabular}

\section{Immunofluorescence}

Immunofluorescence was performed in order to determine the expression of Arc, BDNF and Reelin in the hippocampus, as described in our previous studies (Ni et al., 2015). The rat hippocampus was fixed with $4 \%$ paraformaldehyde for $24 \mathrm{~h}$, cryoprotected with $30 \%$ sucrose for $48 \mathrm{~h}$, and sectioned using a cryostat (Cryotome E, Thermo Fisher, MA, United States). Coronal sections (10 $\mu \mathrm{m}$ thickness) were incubated with Arc antibody (1:200 dilution; Abcam, Cambrige, United Kingdom), BDNF antibody (1:1000 dilution; Abcam, Cambrige, United Kingdom) or Reelin antibody (1:500 dilution; Abcam, Cambrige, United Kingdom) overnight at $4^{\circ} \mathrm{C}$, followed by incubation with goat anti-rabbit IgG conjugated to Alexa Fluor $^{\circledR} 488$ (1:400 dilution; Servicebio, Wuhan, China) for $50 \mathrm{~min}$ at room temperature. Nuclei were subsequently counterstained with DAPI (1:5000 dilution; Servicebio, Wuhan, China) for $10 \mathrm{~min}$ at room temperature. Images were captured using a Nikon Eclipse Ti confocal microscope. Due to the results of previous studies (Lee and Kesner, 2002), the hippocampal subregions CA1 and DG serve important roles in retrieving contextual memory after a long time period (i.e., $24 \mathrm{~h}$ ), these two regions were analyzed for Arc, BDNF and Reelin expressions. Images were acquired by Nikon Eclipse Ti-S microscope (Nikon Corp., Tokyo, Japan).

\section{MassARRAY EpiTYPER Assay}

DNA methylation was quantified by the mass spectrometrybased method MassARRAY EpiTYPER compact MALDI-TOF (Agena Bioscience Inc., San Diego, CA, United States), and the result data were deposited in Dryad Digital Repository ${ }^{1}$. In brief, DNA was extracted from C6 glioma cells and rat hippocampi using Cell/Tissue DNA Extraction Kit (BioTeke, Beijing, China), then was bisulfite converted using Zymo Research EZ DNA Methylation Kit (Zymo Research, Irvine, CA, United States). Primers were designed using the EpiDesigner Software ${ }^{2}$, and their sequences are listed in Table 2. PCR amplification was carried out in an $8 \mu \mathrm{l}$ reaction volume containing $0.8 \mu \mathrm{l}$ of $10 \times$ PCR Buffer, $0.8 \mu \mathrm{l}$ of dNTPs, $0.1 \mu \mathrm{l}$ PCR enzyme, $0.2 \mu \mathrm{l}$ of each primer, $1.0 \mu \mathrm{l}$ of bisulfite-converted DNA and $\mathrm{H}_{2} \mathrm{O}$, and the amplification was carried out with an initial denaturation step at $94^{\circ} \mathrm{C}$ for $4 \mathrm{~min}$ followed by 45 cycles of $94^{\circ} \mathrm{C}$ for $20 \mathrm{~s}, 56^{\circ} \mathrm{C}$ for $30 \mathrm{~s}$, and $72^{\circ} \mathrm{C}$ for $1 \mathrm{~min}$, then final extension at $72^{\circ} \mathrm{C}$ for $3 \mathrm{~min}$. After PCR and Shrimp Alkaline Phosphatase treatment, fragments were ligated to a T7 promoter segment, and then transcribed into RNA. The synthesized RNA was cleaved with RNase A and all cleavage products were analyzed on a mass spectrometer, according to the manufacture's protocol. The generated mass signal patterns were translated into quantitative DNA methylation levels of different CpG sites of the selected genes by MassARRAY EpiTYPER Analyzer software. The locations of promoter regions encompassing the transcription start and the number of $\mathrm{CpG}$ sites assessed in the promoter regions are listed in Table 2. The results were processed and analyzed by the MassARRAY

\footnotetext{
${ }^{1}$ https://doi.org/10.5061/dryad.69p8cz8xw

${ }^{2}$ http://www.epidesigner.com/index.html
} 
TABLE 2 | The primer sequences and assessed locations for Bisulfite sequencing PCR.

\begin{tabular}{|c|c|c|c|c|}
\hline Genes & Orientation & Sequence $\left(5^{\prime}\right.$ to $\left.3^{\prime}\right)$ & Location & CpG sites \\
\hline \multirow[t]{2}{*}{ Arc } & Forward & aggaagagagGGTAGAGGAGAGTGT TाTGGTाT & -274 to +318 & 42 \\
\hline & Reverse & cagtaatacgactcactatagggagaaggctACA CTTACCAATCTACAAAATCACATT & & \\
\hline \multirow[t]{2}{*}{ Bdnf Primer I } & Forward & aggaagagagATTGTGATIIIITGGT AAAAAGGA & -644 to -99 & 16 \\
\hline & Reverse & cagtaatacgactcactatagggagaaggctCCA AAACCCACCTTCTAAAACTTAT & & \\
\hline \multirow[t]{2}{*}{ Bdnf Primer /l } & Forward & 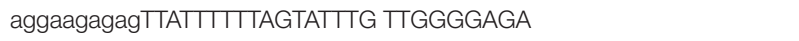 & -634 to -36 & 6 \\
\hline & Reverse & cagtaatacgactcactatagggagaaggctCCTT TCCATATATAAAAACATTACCCA & & \\
\hline \multirow[t]{2}{*}{ Bdnf Primer III } & Forward & aggaagagagTGTTATTTATAATGAA ATGGGTAATGT & -1216 to -730 & 18 \\
\hline & Reverse & cagtaatacgactcactatagggagaaggctACC AAAAATCTATTCCAACCTACAC & & \\
\hline \multirow[t]{2}{*}{ Bdnf Primer $N$} & Forward & aggaagagagTTGTTGTTGTTAGATG ATGAAAGG & -245 to +346 & 18 \\
\hline & Reverse & cagtaatacgactcactatagggagaaggctACC CACCTППTCAATCACTACTTA & & \\
\hline \multirow[t]{2}{*}{ Bdnf Primer VI } & Forward & aggaagagagGAGTITGGGGTTAAG TAGTTGGTT & -192 to +349 & 35 \\
\hline & Reverse & cagtaatacgactcactatagggagaaggctCCT CAAAATCCACACAAAАСТCTC & & \\
\hline \multirow[t]{2}{*}{ Reln } & Forward & aggaagagagGTAGTTAGGTTGAAA GGGAGATTGG & -1383 to -834 & 17 \\
\hline & Reverse & cagtaatacgactcactatagggagaaggctTAA TACCC ППTCCCAAACTCAAAC & & \\
\hline
\end{tabular}

Workstation software. All measurements were performed in triplicate and the average was used for statistical analysis.

\section{Fear Conditioning Test (FCT)}

The FCT (Xeye CPP, Beijing MacroAmbition S\&T Development, Beijing, China) was performed as described in previous studies (Dong and Li, 2014; Cheng et al., 2015) with modification. Briefly, $3 \mathrm{~h}$ after the sevoflurane anesthesia, rats were placed in the context chamber to acclimate for $180 \mathrm{~s}$. Then they received a $2-\mathrm{Hz}$ pulsating tone $(80 \mathrm{~dB}, 3,600 \mathrm{~Hz})$ for $60 \mathrm{~s}$ co-terminated with a mild foot shock $(0.8 \mathrm{~mA}$, a $0.5 \mathrm{~s})$. Contextual FC memory was assessed $48 \mathrm{~h}$ and then 7 days after conditioning, respectively. A contextual test was performed in the same chamber for but with no cues (tone or shock). A cued test was performed by the presentation of same tone without shock in an alternative context with distinct visual and tactile cues. Freezing behavior, recognized as lack of movement except for respiratory efforts, was recorded for $180 \mathrm{~s}$ by video and analyzed using Xeye FCT software. The freezing time was used as an indicator of memory formation during training and memory retrieval after anesthesia. Hippocampal dependent memory was assessed by the freezing time during exposure to a novel context, while hippocampal independent memory was assessed by the freezing time during exposure to the conditional stimulus (tone) (Chowdhury et al., 2005).

\section{Statistical Analysis}

Statistical analysis was performed with Graphpad Prism 7.0 software. Quantitative data were presented as the mean $\pm \mathrm{SD}$ and tested to be normally distributed. Based on the preliminary data, six rats per group was chosen as the sample size for qPCR and DNA methylation studies while twelve per group was selected for FCT experiment to yield a 90\% power and 95\% significance. The Shapiro-Wilk normality test has been used to test if the values of each group come from normal distribution. Non-paired two-tailed Student's $t$-test was used to determine significant differences between two groups. One-way ANOVA was used to analyze significant differences between multiple groups, Bonferroni post hoc analyses were conducted if the main effects were significant. Two-way ANOVA was used to assess the interaction of 5-Aza or SAM with sevoflurane and to test the hypothesis of whether sevoflurane could influence memory gene expression through DNA methylation pathway. Bonferroni post hoc analyses were conducted if the main effects were significant. $P<0.05$ was considered statistically significant.

\section{RESULTS}

\section{Sevoflurane Anesthesia Decreased Arc, $B d n f$, and Reln mRNA and Protein Expression Levels in the Hippocampus of Aged Rats and C6 Glioma Cells}

To find out the gene markers affected by sevoflurane anesthesia within hippocampus of aged rats, we began by examining the expression of five memory genes Arc, Bdnf, Reln, Egrl and Ppp3ca (Hendrickx et al., 2014; Sachser et al., 2016; Duclot and Kabbaj, 2017) using quantitative real-time PCR. Compared with control condition, the mRNA levels of $\operatorname{Arc}(48.36 \pm 13.82$ vs. $100.00 \pm 26.58, P=0.0005), B d n f(46.11 \pm 15.36$ vs. $100.00 \pm 13.4, P=0.0001)$, and Reln (63.61 \pm 22.24 vs. $100.00 \pm 18.60, P=0.0181$ ) decreased significantly $3 \mathrm{~h}$ after $2.5 \%$ sevoflurane anesthesia for $4 \mathrm{~h}$. The decreased mRNA expression of $\operatorname{Arc}(54.30 \pm 13.30, P=0.0015), B d n f(51.26 \pm 16.62$. $P=0.0001)$ persisted for $24 \mathrm{~h}$ after anesthesia, but not for $\operatorname{Reln}(74.00 \pm 22.10, P=0.0984$, Figures 1A-C). No significant differences were observed in the mRNA levels of Egr1 and Ppp3ca $3 \mathrm{~h}$ and $24 \mathrm{~h}$ after sevoflurane anesthesia versus control condition (Egr1, $98.22 \pm 18.71$ and $99.70 \pm 16.29$ vs. $100.00 \pm 15.44$, $P=0.9759$ and 0.9993, respectively; Ppp3ca, $98.06 \pm 20.21$ and $98.20 \pm 21.12$ vs. $100.00 \pm 23.22, P=0.9822$ and 0.9848 respectively, Figures $1 \mathrm{D}, \mathrm{E})$. The time points for observation in the present study were selected based on previous studies and the preliminary study (Lubin et al., 2008; Dyrvig et al., 2015).

To determine the inherent effects of sevoflurane and to obviate the possible physiologic effects of anesthesia, C6 glioma cells were 
A

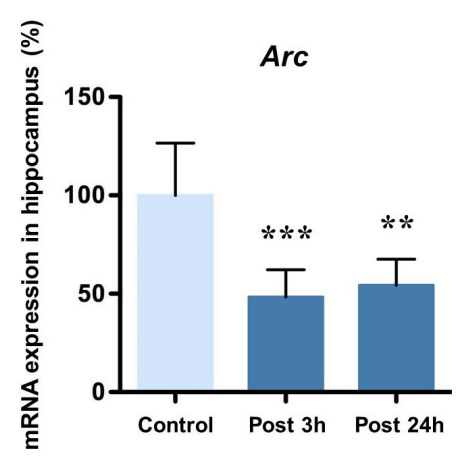

D

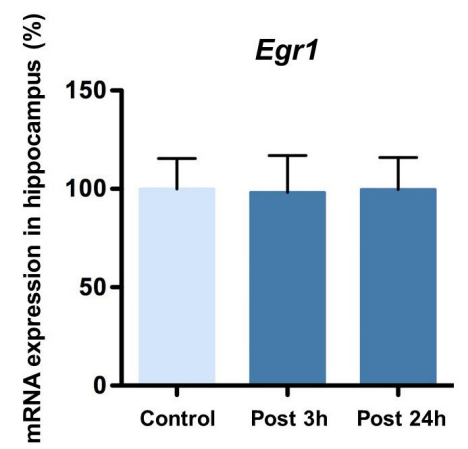

B

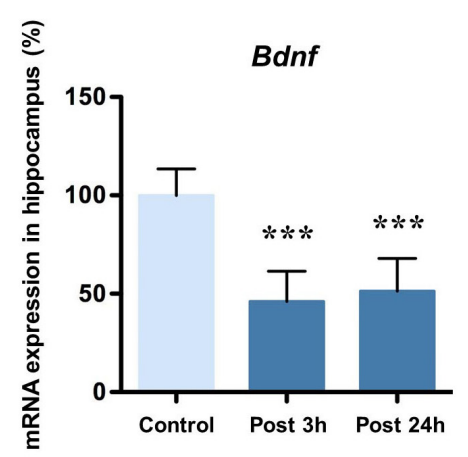

E

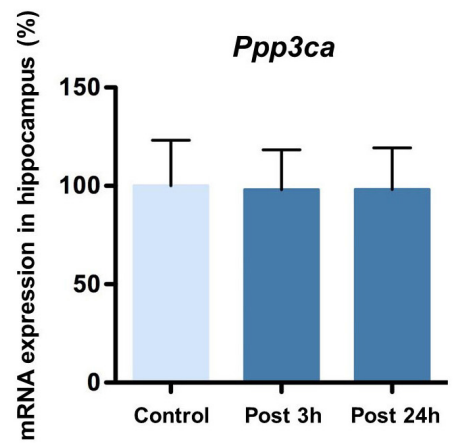

C

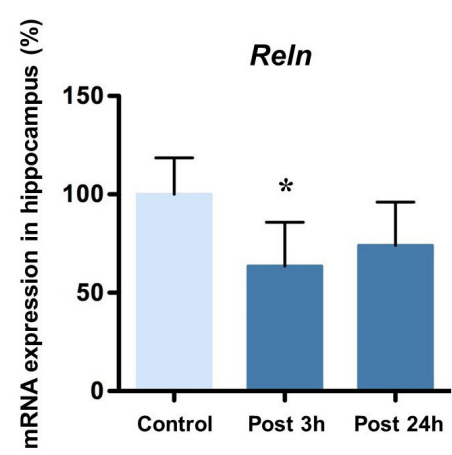

F

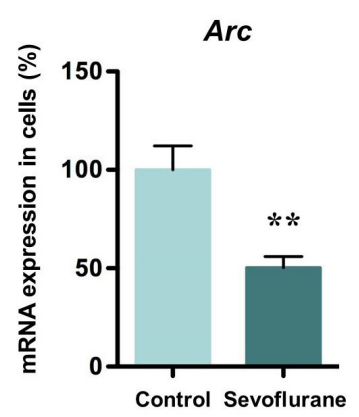

G

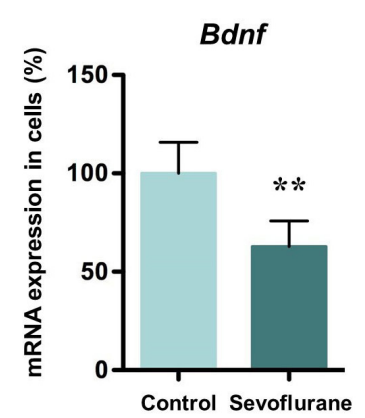

H

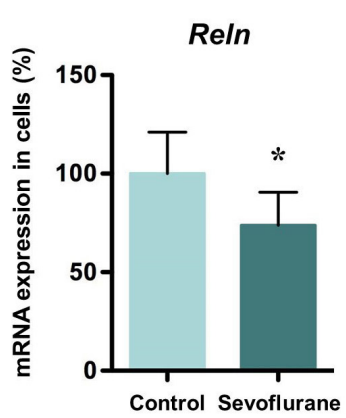

I

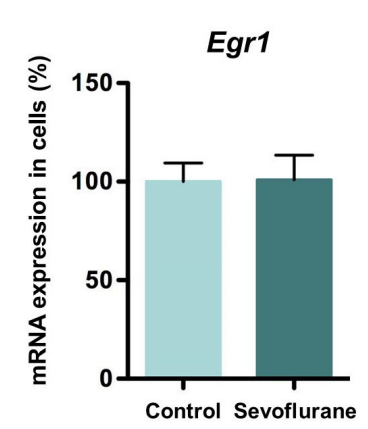

J

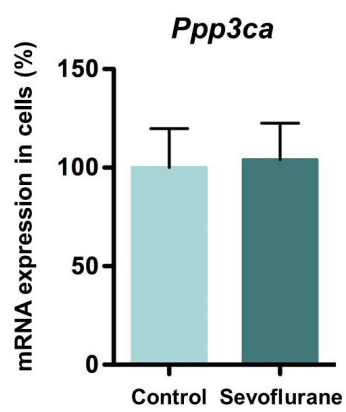

FIGURE 1 | Sevoflurane decreased mRNA levels of Arc, Bdnf and Reln in the hippocampus of aged rats and C6 glioma cells. The mRNA levels of Arc, Bdnf and Reln in the hippocampus of aged rats decreased significantly $3 \mathrm{~h}$ after $4 \mathrm{~h} 2.5 \%$ sevoflurane anesthesia as compared with control condition, and the mRNA levels of Arc and Bdnf, but not Reln, still decreased significantly $24 \mathrm{~h}$ after anesthesia (A-C). The mRNA levels of Egr1 and Ppp3ca did not change after anesthesia (D,E). The mRNA levels of Arc, Bdnf, and Reln in C6 glioma cells decreased significantly after sevoflurane treatment (F-H), but Egr1 and Ppp3ca did not change after treatment $\mathbf{( I , J ) . ~} n=6$ in each group of in vitro and in vivo studies. ${ }^{*} P<0.05,{ }^{\star \star} P<0.01$, and ${ }^{\star \star \star} P<0.001$ compared with the control group.

used. After exposure to $2.5 \%$ sevoflurane for $4 \mathrm{~h}$, the mRNA levels of $\operatorname{Arc}(50.34 \pm 5.635$ vs. $100.00 \pm 12.14, P<0.0001)$, $B d n f(62.83 \pm 12.92$ vs. $100.00 \pm 15.76, P=0.0012)$, and Reln $(73.77 \pm 16.75$ vs. $100.00 \pm 20.99, P=0.0378)$ in C6 glioma cells also decreased significantly (Figures 1F-H). The mRNA levels of Egrl $(100.90 \pm 12.53$ vs. $100.00 \pm 9.48, P=0.8917)$ and $P$ pp3ca $(104.10 \pm 18.46$ vs. $100.00 \pm 19.79, P=0.7185)$ were unchanged after anesthesia (Figures 1I,J). Taken together, these data suggested that anesthesia with sevoflurane decreased mRNA expression levels of Arc, Bdnf and Reln both in vitro and in vivo condition.

Next, we evaluated the immunolabeling of hippocampal Arc, BDNF and Reelin (encoded by $A r c, B d n f$, and Reln, respectively) $3 \mathrm{~h}$ after exposure to after $2.5 \%$ sevoflurane for
$4 \mathrm{~h}$ to determine whether the changes in protein production were corresponded to the alterations in gene transcription. Cytoplasmic and perinuclear Arc staining were detected in the pyramidal cells within CA1 region and in the granule cells within the dentate gyrus (DG). The staining decreased significantly in the sevoflurane group compared to the control condition (Figure 2A). BDNF staining was most prominently observed in the cell bodies and axon terminals in the pyramidal cells within CA1 region and in the granule cells within DG, and the staining decreased significantly in the sevoflurane group (Figure 2B). Reelin is a large secreted extracellular matrix glycoprotein and has been reported to accumulate in oligomeric amyloid-like plaques in the hippocampus of several aged species (Knuesel et al., 2009). Compared to the anesthesia group, Reelin positive cells in 


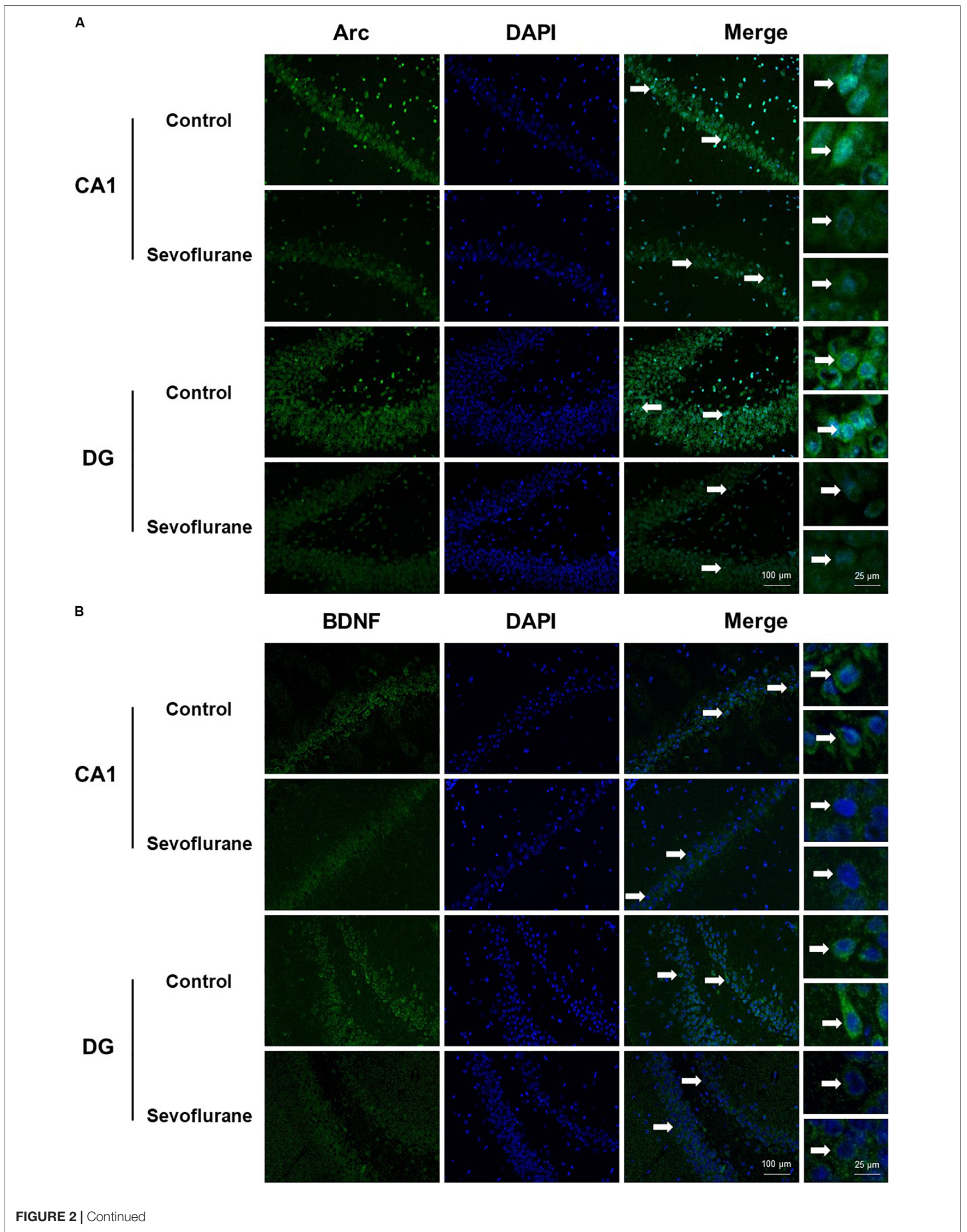




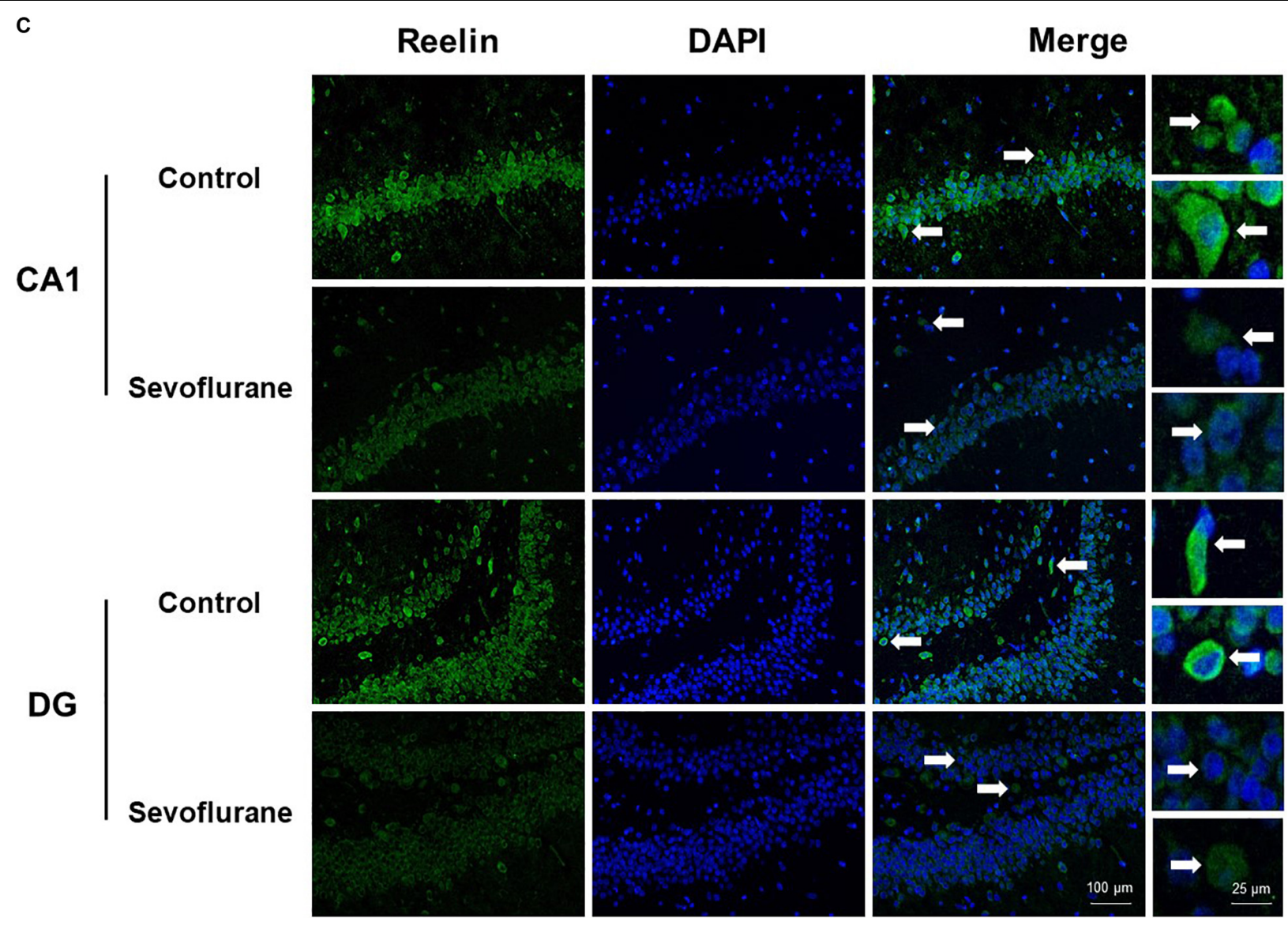

FIGURE 2 | Immunoreactivities of Arc, BDNF, and Reelin decreased in the CA1 region and DG in the hippocampus of aged rats after sevoflurane anesthesia. Immunofluorescence images of hippocampal sections staining with antibodies (green), cell nuclei counter-stained with DAPI (blue) and merged images. Arc staining was detected in the cytoplasm and around the nucleus, and decreased in anesthesia group (A). BDNF staining was most prominently observed in the cell bodies and axon terminals, and decreased in anesthesia group (B). Compared to the anesthesia group, Reelin positive cells were more numerous and polymorphous in control condition (C). In each panel, arrows point to the regions that present typical staining, which are provided as high magnification images in the corresponding right panels. Magnification $400 \times$, scale bar 100 and $25 \mu \mathrm{m}$.

the control condition were more numerous and polymorphous, with smaller interneuron dots possibly representing extracellular Reelin aggregates (Figure 2C).

\section{Sevoflurane Anesthesia Induced \\ Cognitive Impairment in Aged Rats}

To assess whether sevoflurane anesthesia leads to hippocampusdependent cognitive impairments, a subgroup of aged rats was subjected to the fear conditioning test (FCT) $48 \mathrm{~h}$ and 7 days after anesthesia. The results of the context test, mainly used to assess hippocampal function (Li et al., 2014), showed that sevoflurane anesthesia did not alter freezing time at $48 \mathrm{~h}(34.71 \pm 19.77$ vs. $46.59 \pm 20.33, P=0.1609$, Figure $3 \mathrm{~A}$ ), however on day 7 , rats exposed to sevoflurane displayed reduced freezing time $(21.75 \pm 11.32$ vs. $36.29 \pm 13.50, P=0.0091$, Figure $3 \mathrm{C})$ compared to the control group, which suggested that sevoflurane induced hippocampal-dependent cognitive deficits persisted for a relatively long time period. During the tone test, which is related to amygdala function (Li et al., 2014), sevoflurane anesthesia did not alter freezing time at $48 \mathrm{~h}(61.7 \pm 31.05$ vs. $59.87 \pm 26.55$, $P=0.8777$, Figure 3B) or on day $7(45.49 \pm 20.75$ vs. $42.3 \pm 18.19$, $P=0.6933$, Figure 3D), suggesting that amygdala function is not grossly impaired.

\section{Sevoflurane Altered Dnmts and Mecp2 Expression in the Hippocampus of Aged Rats and $\mathrm{C6}$ Glioma Cells}

DNA methylation is catalyzed by three DNA methyltransferases (DNMTs) in mammals, DNMT1, DNMT3a, and DNMT3b. DNMT3a and $3 \mathrm{~b}$ catalyze de novo methylation, while DNMT1 is responsible for the maintenance of previously methylated sites in the adult brain (Robertson et al., 1999). Methyl-CpG binding protein $2(\mathrm{MeCP} 2)$ typically acts as a transcriptional repressor that binds to methylated $\mathrm{CpG}$ and is involved in the maintenance of synaptic plasticity and cognitive functions in the mammal brain (Nan et al., 1997; Fasolino and Zhou, 2017). Given their roles in memory related neuronal plasticity in brain regions such as hippocampus (Lubin et al., 2008; Feng et al., 2010; 
A

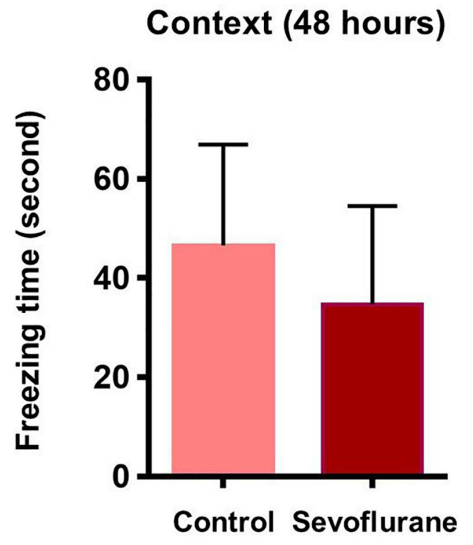

C

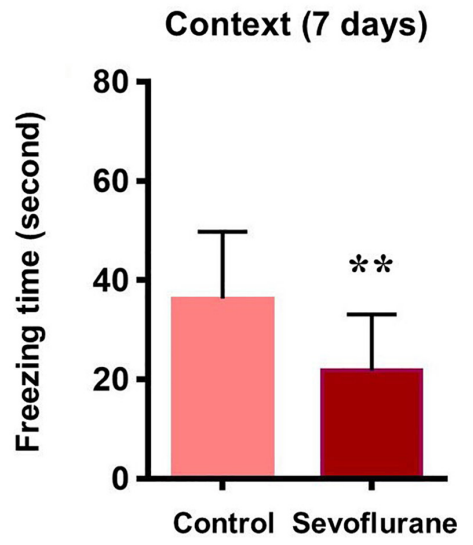

B

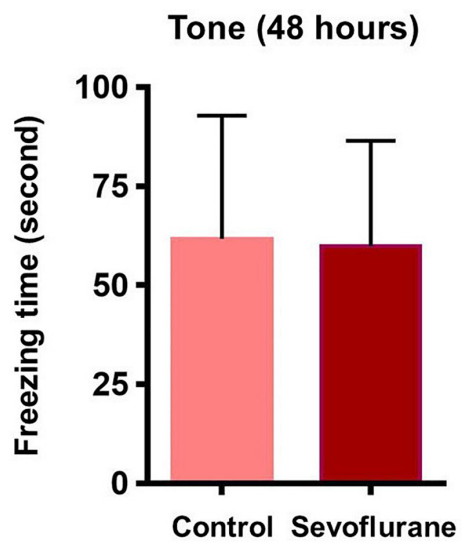

D

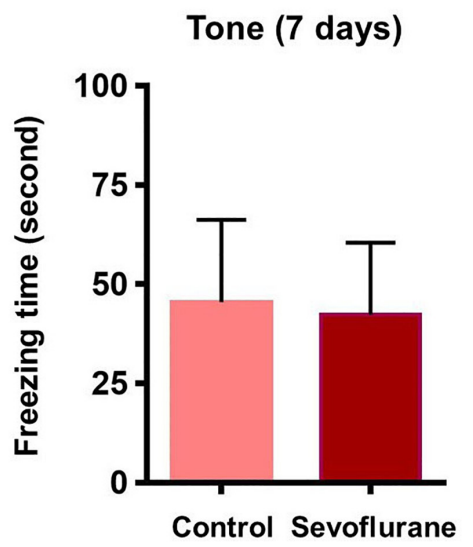

FIGURE 3 | Sevoflurane induced hippocampus dependent memory impairment in aged rats $48 \mathrm{~h}$ after sevoflurane anesthesia, the freezing time did not change in both contextual and tone test of fear conditioning test (A,B). 7 days after sevoflurane anesthesia, the freezing time reduced significantly in context test (hippocampus dependent, $\mathbf{C}$ ), but did not change in tone test (hippocampus independent, $\mathbf{D}$ ). $n=12$ in each group. ${ }^{\star \star} P<0.01$ compared with the control group.

Halder et al., 2016), we investigated whether Dnmts and Mecp2 mRNA levels in the hippocampus of aged rats were altered by sevoflurane. The mRNA levels of Dnmt1 (189.10 \pm 35.94 vs. $100.00 \pm 28.46, P=0.0014)$, Dnmt3a (152.40 \pm 37.15 vs. $100.00 \pm 26.9, P=0.0202)$ and Mecp2 (226.70 \pm 51.79 vs. $100.00 \pm 24.20, P=0.0001$ ) significantly increased $3 \mathrm{~h}$ after sevoflurane exposure compared to the control. The increased transcriptional expression of Dnmt1 (171.30 \pm 43.52 vs. $100.00 \pm 28.46, P=0.0076)$ and $M e c p 2(201.80 \pm 30.15$ vs. $100.00 \pm 24.20, P=0.0005)$ persisted up to $24 \mathrm{~h}$ after sevoflurane treatment, but not for Dnmt3a (128.40 \pm 28.70 vs. $100.00 \pm 26.9$, $P=0.2302$, Figures $4 \mathbf{A}, \mathbf{B}, \mathbf{D})$. However, the Dnmt3b mRNA levels decreased both $3 \mathrm{~h}$ and $24 \mathrm{~h}$ after sevoflurane exposure $(49.51 \pm 16.61$ and $50.97 \pm 12.47$ vs. $100.00 \pm 25.65, P=0.0007$ and 0.0009, respectively, Figure 4C).

The same pattern can be seen with in vitro experiment results. In C6 glioma cells, the mRNA levels of Dnmt1 $(141.00 \pm 26.30$ vs. $100.00 \pm 21.41, P=0.0142$, Figure 4E), Dnmt3a (132.20 \pm 23.42 vs. $100.00 \pm 25.62, P=0.0464$, Figure 4F) and $\operatorname{Mecp} 2(140.30 \pm 31.41$ vs. $100.00 \pm 30.37$,
$P=0.0472$, Figure 4G) increased and Dnmt3b mRNA levels decreased $(100.00 \pm 16.62,77.72 \pm 17.15, P=0.0453$, Figure 4H) after sevoflurane anesthesia. Assuming that Dnmts mRNA and protein levels correlate with DNA methylation levels (Fasolino and Zhou, 2017), therefore it is reasonable to speculate from these data that sevoflurane triggers hippocampal hypermethylation by dynamically upregulating Dnmt1, Dnmt3a and Mecp 2 expression.

\section{Sevoflurane Altered the Promoter Methylation Status of Arc, Bdnf, and Reln in the Hippocampus of Aged Rats and 66 Glioma Cells}

To evaluate whether anesthesia induced hypermethylation in the hippocampus was responsible for the reduced transcripts, we then went on to investigate the methylation status of the promoter regions of $A r c, B d n f$ and Reln in the hippocampus of aged rats. Thus, methylation-specific qPCR was applied. Analysis of the overall methylation of the $\mathrm{CpG}$ sites revealed a substantial 


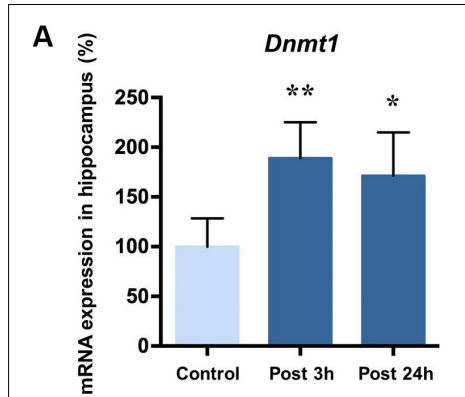

E

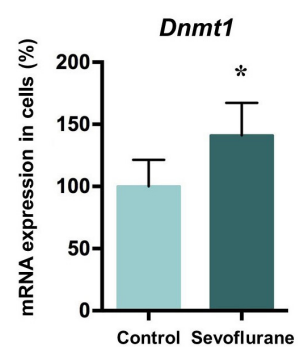

B

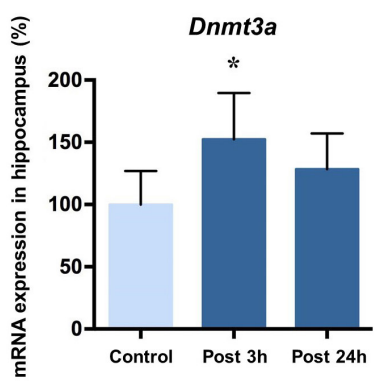

$\mathbf{F}$

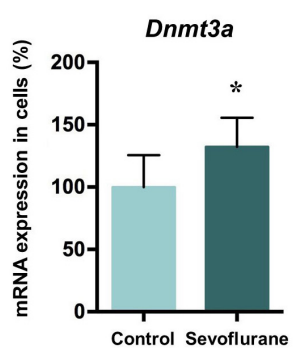

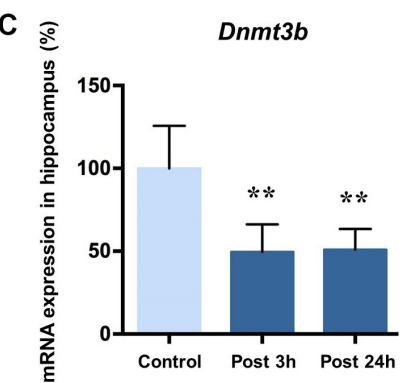

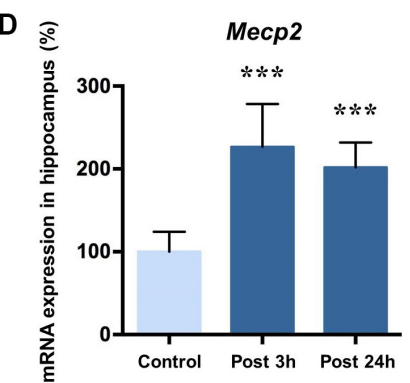

G

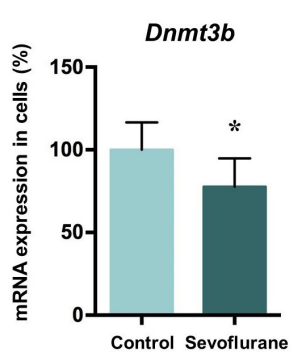

H

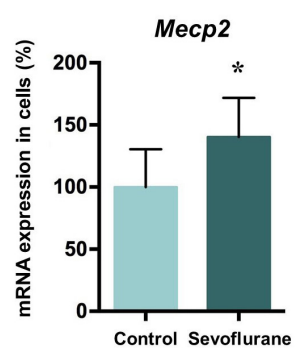

FIGURE 4 | Sevoflurane increased Dnmt1, Dnmt3a, and MeCP2 mRNA levels and decreased Dnmt3b mRNA levels in the hippocampus of aged rats and C6 glioma cells. The mRNA levels of Dnmt1, Dnmt3a, and MeCP2 in the hippocampus of aged rats increased significantly $3 \mathrm{~h}$ after $4 \mathrm{~h} 2.5 \%$ sevoflurane anesthesia as compared with control condition, and the mRNA levels of Dnmt1 and MeCP2, but not Dnmt3a, still increased significant $24 \mathrm{~h}$ after anesthesia (A,B,D). Dnmt3b mRNA levels in the hippocampus of aged rats decreased significantly $3 \mathrm{~h}$ and $24 \mathrm{~h}$ after anesthesia (C). The mRNA levels of Dnmt1, Dnmt3a and MeCP2 in C6 glioma cells increased significantly after sevoflurane treatment (E,F,H), and the mRNA levels of Dnmt3b in C6 glioma cells decreased significantly after treatment (G) $n=6$ in each group of in vitro and in vivo studies. ${ }^{*} P<0.05,{ }^{\star *} P<0.01$, and ${ }^{\star \star *} P<0.001$ compared with the control group.

increase in the $\operatorname{Arc}$ promoter regions after anesthesia $(P=0.0143$, Figure 5A). More specifically, a significant increase in DNA methylation was observed at the following individual $\mathrm{CpG}$ sites $(P<0.05)$ : TSS (transcription start site) -147 , TSS +11 , TSS +30 , TSS +58 , TSS +98 , TSS +121 , TSS +141 , TSS +207 and TSS +252 . Also, sevoflurane induced a significant increase in the overall methylation at $B d n f$ promoter I $(P=0.0418$, Figure 5B). The highly methylated CpG sites were: TSS -176 , TSS -180 , TSS -254 , TSS -329 , TSS -380 , TSS -528 , and TSS $-577(P<0.05)$. The overall methylation of $B d n f$ promoter III, IV, VI was not different between control and sevoflurane groups (Figures 5DF), but a significant increase in DNA methylation were observed in 5 CpG residues of $B d n f$ promoter III (TSS -1115 , TSS -1005 , TSS -884 , TSS -868 , and TSS $-817 ; P<0.05$, Figure 5D), 4 residues of $B d n f$ promoter IV (TSS-197, TSS -176 , TSS -24 , and TSS $+216 ; P<0.05$, Figure 5E) and 3 residues of $B d n f$ promoter VI (TSS -98 , TSS +164 , and TSS $+292 ; P<0.05$, Figure 5F) in the sevoflurane group. Bdnf promoter II showed no change of methylation status in any of the CpG sites after anesthesia (Figure 5C). Overall methylation of Reln promoter was not different for control and anesthetized rats (Figure 5G). However, a significant increase in DNA methylation was observed in $2 \mathrm{CpG}$ residues of Reln promoter (TSS -967 and TSS -1333) in the sevoflurane group $(P<0.05$, Figure 5G).

In vitro experiments with C6 glioma cells exhibited the same trends of increased methylation in the $\operatorname{Arc}$ promoter $(P=0.0037)$ and $B d n f$ promoter I $(P=0.0120)$ regions after sevoflurane treatment. Arc promoter was hypermethylated at TSS -147 , TSS -61 , TSS -51 , TSS +30 , TSS +58 , TSS +98 , TSS +121 ,
TSS +141 and TSS $+207(P<0.05$, Figure 6A). And $B d n f$ promoter I was hypermethylated at TSS -180 , TSS -268 , TSS -329, TSS -528 , and TSS $-577(P<0.05$, Figure 6B). We observed no significant difference in the overall methylation status of Bdnf promoter II, III, IV, VI and Reln promoters. However, sevoflurane induced several hypermethylated CpG sites in $B d n f$ promoter III (TSS-1115 and TSS -868; $P<0.05$, Figure 6D), promoter IV (TSS-197, TSS -176, and TSS +216; $P<0.05$, Figure 6E), promoter VI (TSS +120 , TSS +164 , and TSS +277; $P<0.05$, Figure 6F), and Reln promoter (TSS -863, TSS -967, and TSS - 1333; $P<0.05$, Figure 6G). There was no change of methylation status in any of the $\mathrm{CpG}$ sites in Bdnf promoter II (Figure 6C). These data suggest that CpGs hypermethylation at particular sites in the promoter could involve in transcriptional suppression of $A r c, B d n f$ and Reln in response to sevoflurane treatment.

\section{DNA Methylation Manipulation Affected the Sevoflurane Induced Memory Gene Transcription Decrease in C6 Glioma Cells}

To determine whether the increased DNA methylation could account for decreased expression of Arc, Bdnf and Reln gene after sevoflurane, we firstly treated C6 glioma cells with pharmacological inhibitor 5-Aza-2'-deoxycytidine (5-Aza, $10 \mu \mathrm{M}$ in cell culture) $60 \mathrm{~min}$ before sevoflurane anesthesia. 5-Aza is a nucleoside inhibitor incorporated into DNA by covalent binding and thereby blocking its DNA methyltransferase 


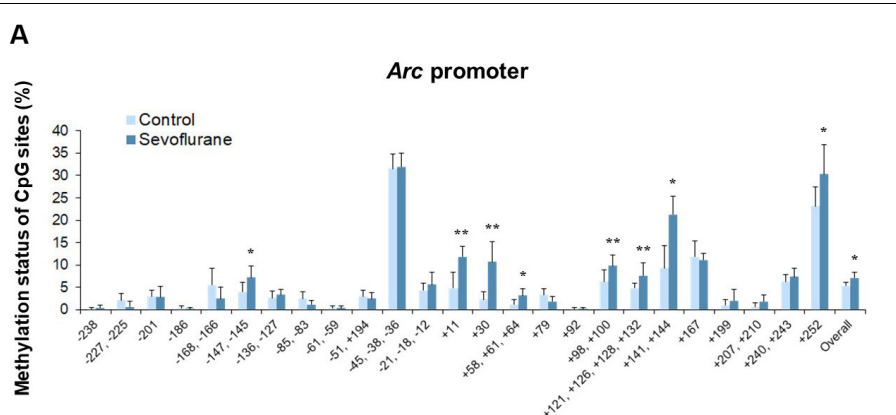

CpG position relative to TSS

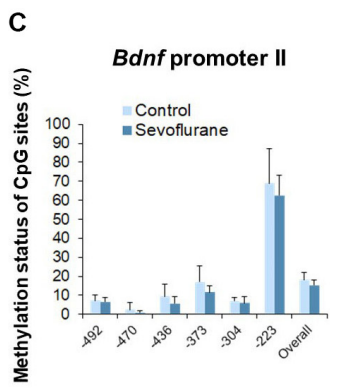

CpG position relative to TSS

\section{D}

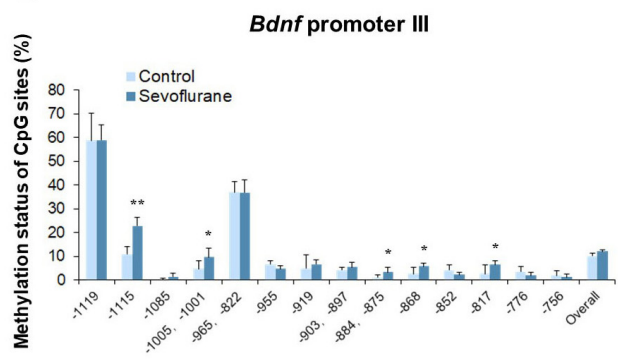

CpG position relative to TSS

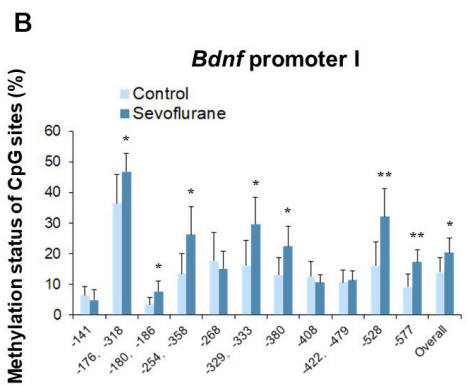

CpG position relative to TSS

E

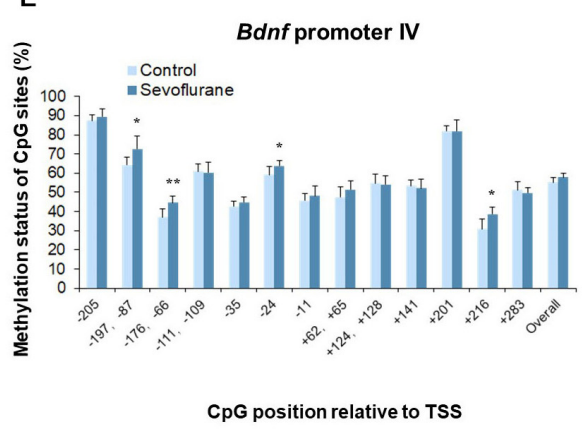

F

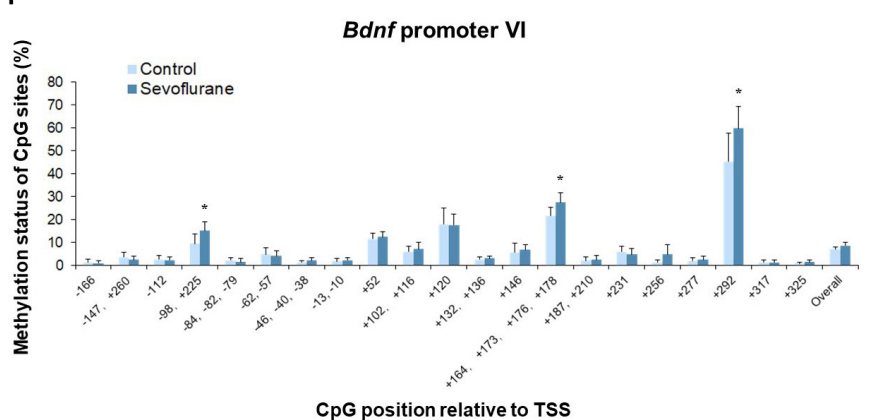

G

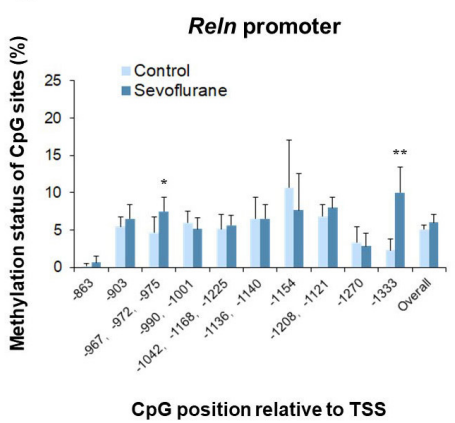

FIGURE 5 | Sevoflurane induced hypermethylation status of Arc, Bdnf and Reln promoters in the hippocampus of aged rats. The frequency of methylation was observed at each CpG site in the Arc, Bdnf and Reln promoter regions in the hippocampus of aged rats after sevoflurane anesthesia. The overall methylation increased significantly in the Arc promoter and Bdnf promoter I, The DNA methylation increased at individual CpG sites in the Arc promoter, Bdnf promoter I, III, IV, $\mathrm{VI}$, and Reln promoter, but not Bdnf promoter II (A-G). $n=6$ in each group. ${ }^{\star} P<0.05$ and ${ }^{\star *} P<0.01$ compared with the control group.

function (Navada et al., 2014). In the control condition, 5-Aza alone did not affect $\operatorname{Arc}(125.20 \pm 18.01$ vs. $100.00 \pm 18.02$, $P=0.0512), B d n f(109.50 \pm 20.87$ vs. $100.00 \pm 14.62, P=0$. $5509)$ or $\operatorname{Reln}(103.90 \pm 19.12$ vs. $100.00 \pm 18.92, P=0.8985)$ mRNA levels. However, 5-Aza was found to attenuate decreased mRNA expression of $\operatorname{Arc}(46.17 \pm 19.91$ vs. $102.90 \pm 16.61$, $P<0.0001), B d n f$ (70.86 \pm 10.84 vs. $109.20 \pm 17.87, P=0.0013)$ and $\operatorname{Reln}(72.13 \pm 13.79$ vs. $97.27 \pm 11.14, P=0.0272)$ induced by sevoflurane. Two-way ANOVA yielded that the interaction of 5-Aza and sevoflurane treatment was significant for the mRNA levels of $\operatorname{Arc}(P=0.0467), B d n f(P=0.0449)$, but not for Reln $(P=0.1217$, Figures 7A-C).

Next, we treated C6 glioma cells with methyl donor S-Adenosyl methionine (SAM, $100 \mu \mathrm{M}$ in cell culture) $60 \mathrm{~min}$ before sevoflurane treatment to induce DNA hypermethylation. Decreased the mRNA expressions of Arc (67.57 \pm 11.69 vs. $100.00 \pm 18.02, P=0.0042), B \operatorname{dnf}(81.45 \pm 9.97$ vs. $100.00 \pm 14.62, P=0.0386)$ and $\operatorname{Reln}(61.57 \pm 16.49$ vs. $100.00 \pm 18.92, P=0.0009)$ were observed in the control condition. But SAM had no effect on $\operatorname{Arc}$ (45.11 \pm 16.54 vs. $45.17 \pm 19.91, P=0.9222), B d n f(68.11 \pm 14.47$ vs. $70.90 \pm 10.85$, $P=0.9136)$ and $\operatorname{Reln}(61.42 \pm 13.40$ vs. $72.13 \pm 13.79, P=0.4437)$ mRNA levels in the sevoflurane group. The interaction of SAM and sevoflurane treatment was significant for the mRNA levels of $\operatorname{Arc}(P=0.0336)$ and $\operatorname{Reln}(P=0.0441)$, but not for $B d n f$ $(P=0.1428$, Figures 7D-F). Therefore, manipulating DNA methylation by 5 -Aza is sufficient to restore suppressed memory genes transcription by sevoflurane. 


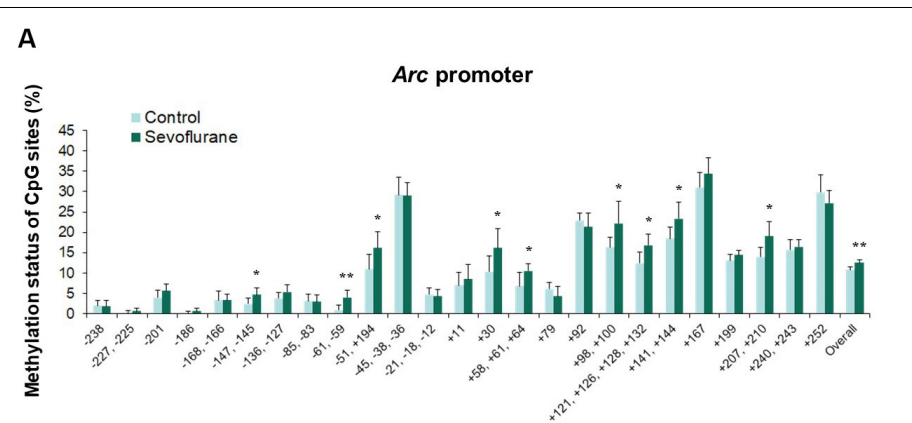

CpG position relative to TSS

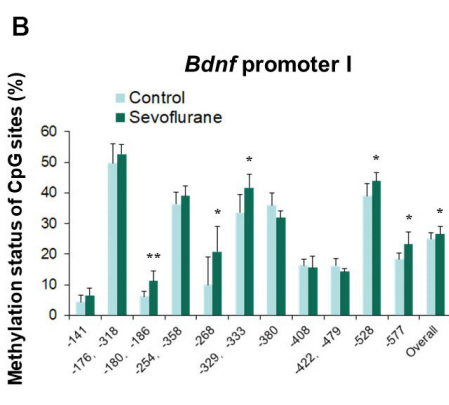

CpG position relative to TSS

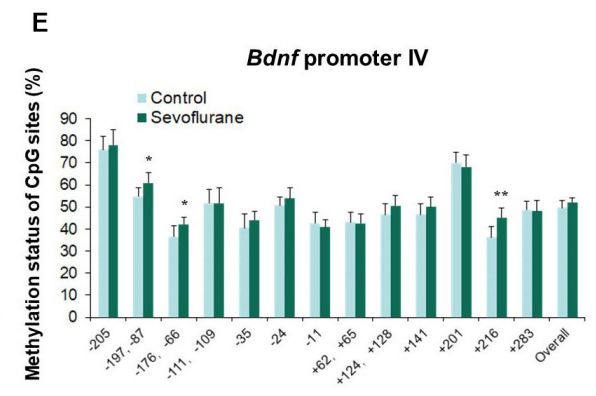

CpG position relative to TSS

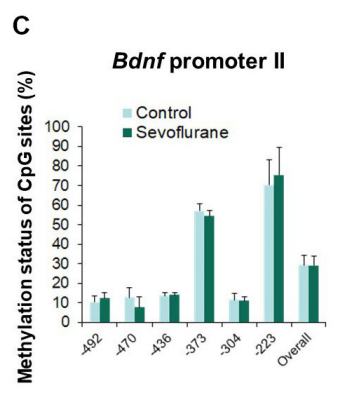

CpG position relative to TSS

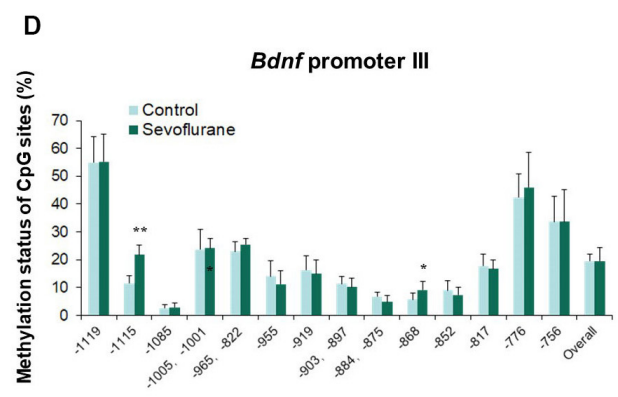

CpG position relative to TSS

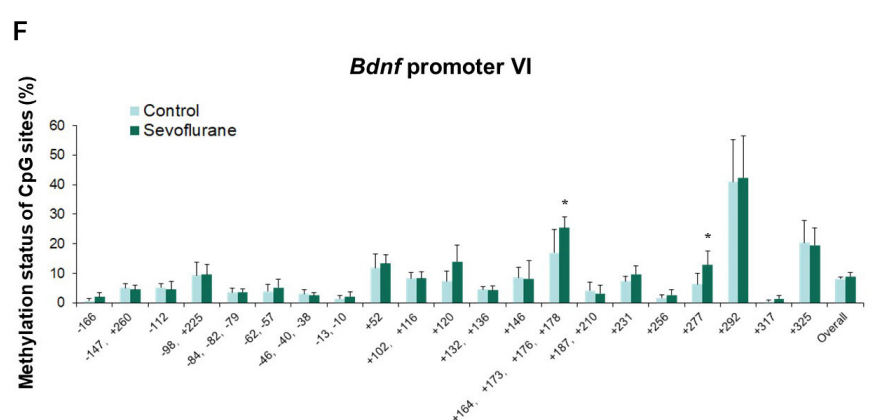

CpG position relative to TSS

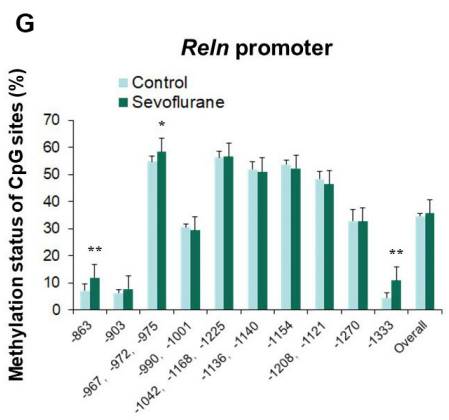

CpG position relative to TSS

FIGURE 6 | Sevoflurane induced hypermethylation status of Arc and Bdnf promoters in C6 glioma cells. The frequency of methylation was observed at each CpG site in the Arc, Bdnf and Reln promoter regions in C6 glioma cells after sevoflurane treatment. The overall methylation increased significantly in the Arc promoter and Bdnf promoter I, The DNA methylation increased at individual CpG sites in the Arc promoter, Bdnf promoter I, III, IV, VI and Reln promoter, but not Bdnf promoter II (A-G). $n=6$ in each group. ${ }^{\star} P<0.05$ and ${ }^{\star \star} P<0.01$ compared with the control group.

\section{DNA Methylation Inhibition Attenuated the Sevoflurane Anesthesia Induced Hippocampal Memory Gene Transcription Decrease and Cognitive Impairment in the Aged Rats}

As DNA methylation inhibition partially restored the downregulation of memory gene transcription induced by sevoflurane in vitro, we further investigated its effects on hippocampal memory genes and cognitive function in the aged rats. 5-Aza treatment $(0.5 \mathrm{mg} / \mathrm{kg}$ i.p., $30 \mathrm{~min}$ before anesthesia) attenuated decreased mRNA levels of $\operatorname{Arc}(100.5 \pm 14.56$ vs. $58.34 \pm 13.35$, $P=0.0012), B d n f(96.49 \pm 20.04$ vs. $56.92 \pm 10.41, P=0.0007)$ and $\operatorname{Reln}(94.03 \pm 14.35$ vs. $70.94 \pm 9.06, P=0.0082)$ in the hippocampus resulting from sevoflurane anesthesia. But 5-Aza alone did not significantly affect hippocampal Arc (100.5 \pm 14.56 vs. $58.34 \pm 13.35, P=0.5372), B d n f(110.60 \pm 18.12$ vs. $100.00 \pm 23.86, P=0.3946)$ or Reln (114.30 \pm 13.80 vs. $100.00 \pm 11.43, P=0.1127)$ mRNA levels. The interaction of 5-Aza and sevoflurane treatment was significant for the mRNA levels of $\operatorname{Arc}(P=0.0435)$ and $B d n f(P=0.0454)$, but not for Reln $(P=0.3947$, Figures 8A-C).

Having confirmed that the cognitive impairment was evident at 7 days after sevoflurane in context test, and correlated with the changes in transcriptional and methylation profiles of memory genes in the aged rats, we then examined the effect of DNA methylation inhibition on cognitive function in context test at 7 days after anesthesia. The results indicated that 5-Aza 
A

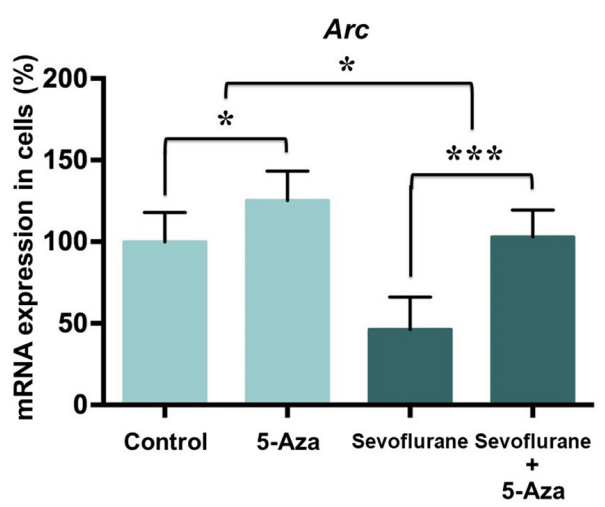

C

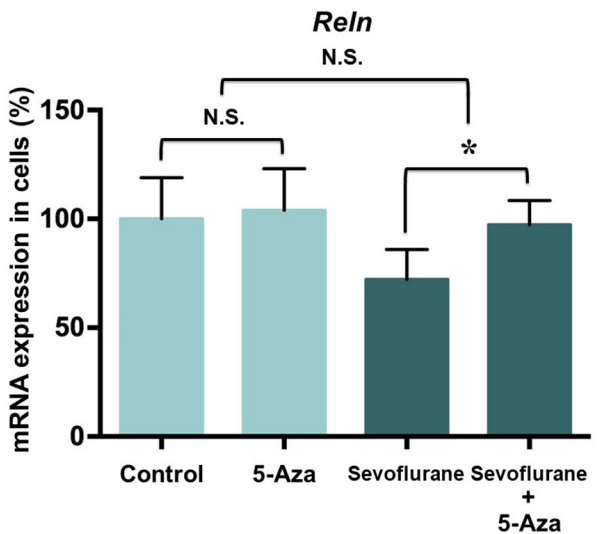

E

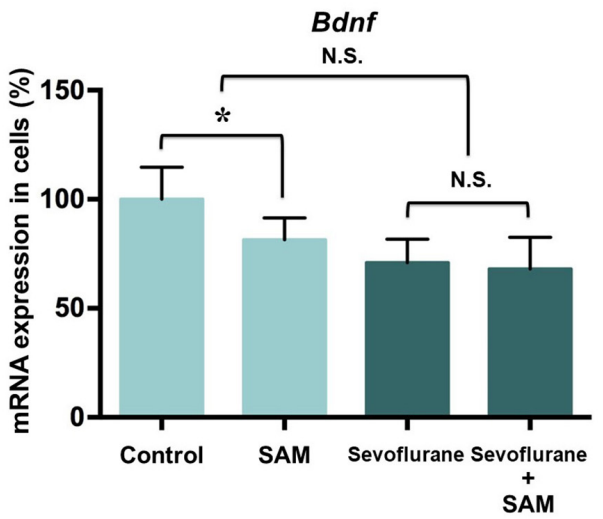

B

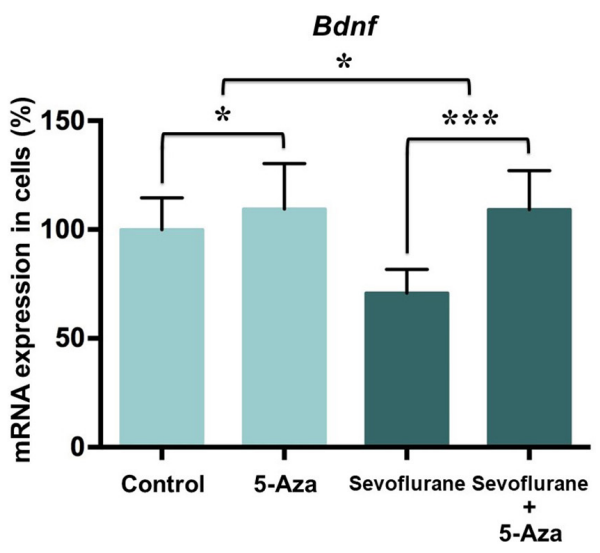

D

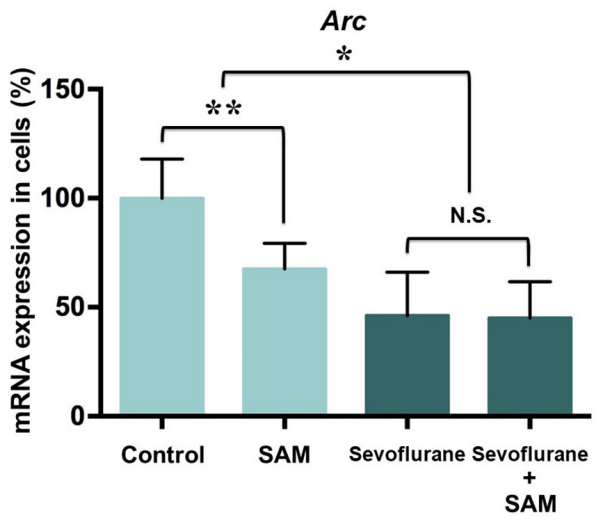

$\mathrm{F}$

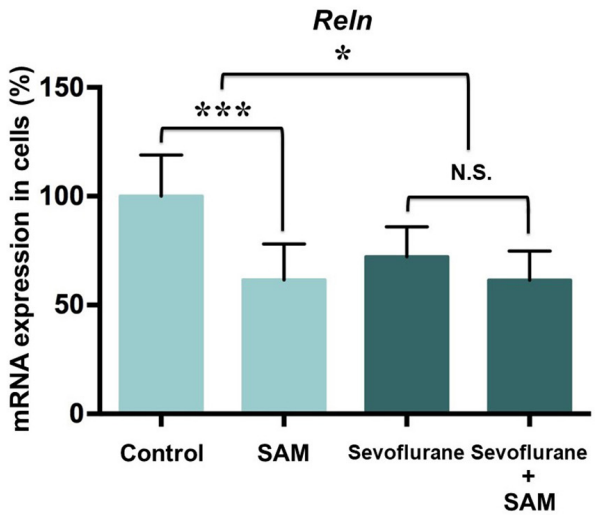

FIGURE 7 | DNA methylation manipulation affected the sevoflurane induced Arc, Bdnf and Reln transcription decrease in C6 glioma cells. DNMT antagonist 5-Aza administration 60 min before sevoflurane treatment attenuated sevoflurane induced Arc, Bdnf, and Reln mRNA level decrease, but 5-Aza alone did not affect Arc, Bdnf and Reln mRNA levels in C6 glioma cells (A-C). Methyl donor SAM C6 glioma cells administered with 60 min before treatment did not affect Arc, Bdnf and Reln mRNA level after sevoflurane treatment, but SAM alone decreased the mRNA expression of Arc, Bdnf and Reln mRNA levels in C6 glioma cells (D-F). $n=6$ in each group. ${ }^{\star} P<0.05,{ }^{\star \star} P<0.01$, and ${ }^{\star \star \star} P<0.001$ compared with the control or sevoflurane group. N.S., not significant.

treatment attenuated the reduced freezing time $(33.47 \pm 14.41$ vs. $13.93 \pm 9.268, P=0.0042)$ in aged rats after sevoflurane anesthesia. But 5-Aza alone did not significantly affect the freezing time in the control condition (36.53 \pm 17.24 vs. $37.17 \pm 16.29, P=0.9930)$. The interaction of 5 -Aza and sevoflurane treatment was significant for a relatively long period $(P=0.0213$, Figure 8D). Collectively, these findings indicate that decreased $A r c, B d n f$ and Reln expressions in the hippocampus are medicated by promoter hypermethylation, which is involved in the upstream mechanisms for sevoflurane induced cognitive impairment in aged rats.

\section{DISCUSSION}

In the present study, we found that sevoflurane anesthesia down-regulated the mRNA and protein levels of three memory genes, Arc, Bdnf and Reln, which were accompanied with 
A

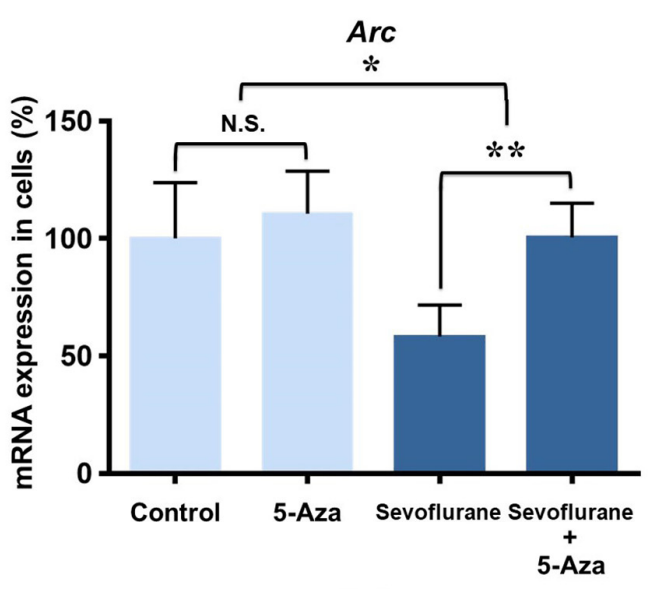

C

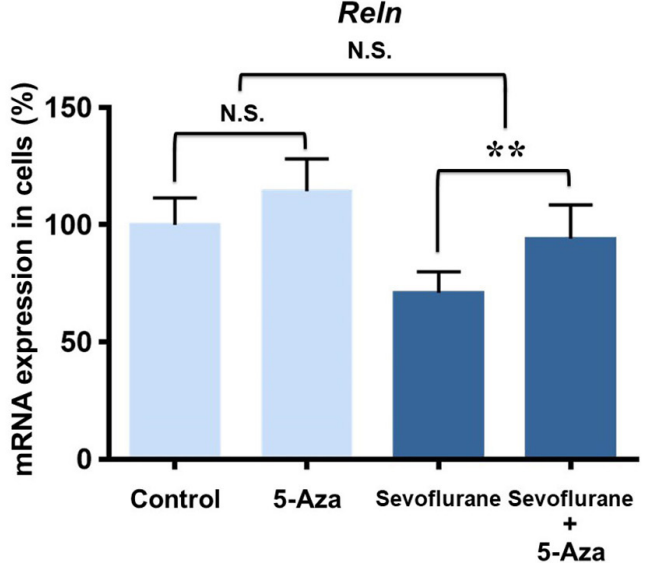

B

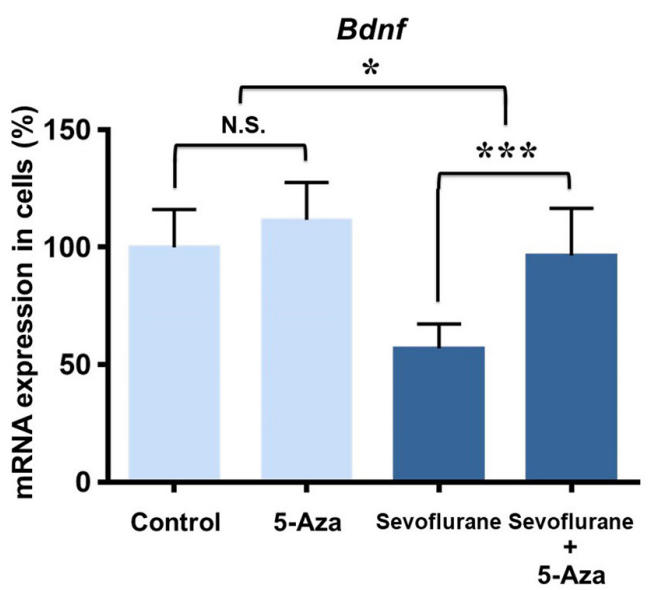

D

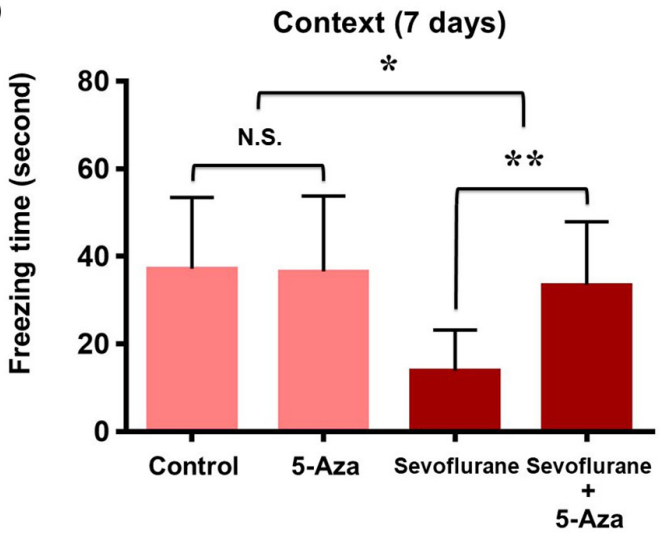

FIGURE 8 | DNA methylation inhibition attenuated the sevoflurane induced hippocampal Arc, Bdnf and Reln transcription decrease and cognitive impairment in the aged rats. DNMT antagonist 5-Aza administration 30 min before sevoflurane anesthesia attenuated sevoflurane induced Arc, Bdnf and Reln mRNA level decrease, but 5-Aza alone did not affect Arc, Bdnf and Reln mRNA levels in the hippocampus of aged rats (A-C). 5-Aza attenuated sevoflurane induced freezing time decrease, but 5-Aza alone did not affect the freezing time in the context test of FCT in aged rats at 7 days after anesthesia (D). $n=6$ in each group for qPCR, and $n=12$ in each group for FCT. ${ }^{\star} P<0.05$, ${ }^{\star \star} P<0.01$, and ${ }^{\star \star \star} P<0.001$ compared with the control or sevoflurane group. N.S., not significant.

promoter hypermethylation and increased Dnmt1, Dnmt3a and Mecp2 expression, and finally impaired hippocampus dependent memory. Furthermore, inhibition of DNA hypermethylation by 5-Aza rescued sevoflurane induced memory gene expression decrease and cognitive impairment. These findings suggest that anesthesia induced epigenetic modulations could be responsible for the long term cognitive impairment in aged rats.

Cognitive processes, such as the fear conditioning test, require transcription of a wide array of genes encoding neurotrophins, pre-synaptic, and post-synaptic proteins and cytoskeletal elements responsible for different types of plasticity events and memory processes in hippocampus, a brain region vulnerable to the aging process (Lubin et al., 2008; Carmichael and Henley, 2018). Both loss and gain of function manipulations to these activity-regulated genes, including $A r c, B d n f$, Reln, Egr1 and Ppp3ca, have been associated with cognitive deficits during physiological aging and pathological conditions like dementia, neurodegenerative diseases and neuropsychiatric problems (Nonaka et al., 2014). In the present study, we report that attenuated transcriptions and protein synthesis of Arc,
$B d n f$ and Reln genes may contribute to hippocampus dependent memory deficits in the aged rats after sevoflurane anesthesia. Combined with previous studies with isoflurane (Bunting et al., 2015; Dalla Massara et al., 2016), we further investigate the transcriptional regulatory mechanisms to drive the coordinated response of multiple memory genes to inhaled anesthesia.

Epigenetic changes in the brain are critical for the long term memory storage through altering genes transcription that are associated with synaptic plasticity during development and throughout adult life (Hwang et al., 2017). Growing number of studies suggest that anesthesia induces a variety of epigenetic modifications in neonatal brain, leading to developmental neurological disorders in animal models (Dalla Massara et al., 2016; Ju et al., 2016; Wu et al., 2016; Jia et al., 2017; Joksimovic et al., 2018). In the present study, we focused on the contribution of DNA methylation to memory genes during anesthesia in aged rats. DNMT inhibition can impair memory formation as well as long-term potentiation (LTP) at CA1 synapses (Feng et al., 2010). DNMT activity and global DNA methylation are decreased in rat brain during aging (Liu et al., 2009) and brain samples from AD 
patients (Liu et al., 2011). Our results showed that sevoflurane increased Dnmt1, Dnmt3a and Mecp2 expressions, resulted in DNA hypermethylation in the promoter regions of Arc, Reln and $B d n f$, and suppressed transcription of these genes. These results are consistent with work in the hippocampus by Levenson et al. (2006), Dyrvig et al. (2015).

DNA methylation has been reported to play key roles in memory formation and maintenance. Accumulating evidence suggests that DNA methylation is dynamically regulates the function of neurons in response to learning experience (Miller et al., 2010). Abnormal hypermethylation or hypomethylation could both lead to memory dysfunction (Ehrlich, 2019), and correlate with multiple neurological disorders, including $\mathrm{AD}$ (manifested as neuronal loss and dementia) (Semick et al., 2019). DNA methylation modulation related gene transcription variations play a key role during these processes. DNA methylation occurs preferentially on $\mathrm{CpG}$ sites. There are a large number of $\mathrm{CpG}$ islands in promoter regions, which could change the original configuration of the promoters in the genes, interfere the combination of specific transcription factors and specific recognition sites, affect the transcription of downstream genes, and result in the abnormal transcription of memory genes (Zhu et al., 2016).

Our intervention studies indicated that SAM decreased the expressions of Arc, Bndf and Reln in control condition (the DNA methylation status were in normal levels and relatively sensitive to the supplementation of methyl donor), but not after sevoflurane in cells (with anesthetic induced hypermethylation). Meanwhile, 5-Aza affect the gene expressions after sevoflurane exposure (with hypermethylation), but not in control condition. The interactions were significant in both studies, which indicated that DNA methylation modification could be a pivotal mechanism for the effects of sevoflurane exposure on memory genes. Furthermore, accompanied with memory gene expression increase, 5-Aza also attenuated sevoflurane induced cognitive impairment in aged rats. Thus, the combination of external factor (sevoflurane) and internal factor (aging) increased the susceptibility to DNA methylation in the hippocampus, which in turn led to the decrease of memory gene expressions and cognitive impairment.

Among these memory genes, BDNF is a member of neurotrophins, which influence neuronal proliferation and differentiation, modulate LTP induction and maintenance, and contribute to the maintenance of synaptic plasticity in the central neurons (Lubin et al., 2008). The rodent $B d n f$ gene has nine exons, eight of which have their own promoter contains multiple promoters that are specifically regulated by different stimuli (Aid et al., 2007). Kainic acid, a glutamate analog, induced transcription of Bdnf exons I, IV, V VII, VIII and IXA in rat hippocampus while $\mathrm{N}$-methyl-d-aspartate (NMDA) treatment identified Bdnf exons II and IV, but not I and III, as fast reacting exons (Aid et al., 2007; Palomer et al., 2016a). This epigenetic modification of $B d n f$ transcription may largely change its expression and contribute to the pathogenesis of several neurological disorders. For instance, aging reduced basal levels, while fear conditioning increased expression of total Bdnf mRNA and exon IV specific transcripts (Chapman et al., 2012). In animal models of AD, occupancy of HDAC2 in the promoter region of $B d n f$ exon IV contribute to the reduction of BDNF in APP/PS1 mice (Hsiao et al., 2017) and infusion of amyloid fibrils into the hippocampus of rats induces HDAC2 occupancy at promoter VI of Bdnf and thus decreases Bdnf expression (Hendrickx et al., 2014). In our study, increased cytosine methylations were observed in the promoter region of Bdnf exon I, III, IV, and VI, which may contribute to the long lasting hippocampal BDNF reduction induced by general anesthesia.

The immediate early gene Arc, which interacts with the NMDA receptor complex, is activated during synaptic activation and memory consolidation (Gao et al., 2018). Arc promoter contains CpG sites and intragenic locus that recruit methylDNA binding proteins (Epstein and Finkbeiner, 2018). Penner et al. (2011) reported that increased methylation of Arc in aged rats might be responsible for age related processes. Calcium influx through NMDA receptors could activate a signaling cascade resulting in CREB phosphorylation and CREB binding protein association. Subsequently, phosphorylated $\mathrm{MeCP} 2$ is dissociated from methylated DNA and leads to transcriptionally active chromatin, then affects $\operatorname{Arc}$ (Epstein and Finkbeiner, 2018) and Bdnf (Palomer et al., 2016a,b) expression. Inhaled anesthetic at clinically relevant concentrations has been shown to inhibit NMDA currents (Haseneder et al., 2013). Thus, NMDA receptor activation could be the upstream mechanism for the epigenetic regulation of $A r c, B d n f$ and other memory genes.

Reln encodes an extracellular matrix protein that contacts postsynaptic dendritic spines to controls glutamatergic neurotransmission through differential modulation of NMDA and AMPA receptor activity, and is critical for synaptic plasticity and memory formation (Doehner and Knuesel, 2010; Telese et al., 2015). Impaired Reelin signaling has a devastating effect on the gross morphology of the hippocampus and involves in pathological forms of aging, such as late-onset $\mathrm{AD}$ (Doehner and Knuesel, 2010; Pujadas et al., 2014). Consistent with the present results, changes in $\mathrm{MeCP} 2$ binding and hypermethylation in Reln promoter are associated with major mental illnesses such as Schizophrenia, bipolar disorder (Mitchell et al., 2005; Zhubi et al., 2014; Teroganova et al., 2016). The results showed that 5-Aza, DNA methyltransferase inhibitor, has a potential therapeutic effect on anesthesia induced memory impairment through affecting the methylation status of Arc, Bdnf and Reln. Moreover, 5-Aza has also been reported to induce demethylation by blocking DNMT enzyme activity at Arc promoter in rat hippocampus (Singh et al., 2015), Bdnf promoter I in mouse Neuro-2a cells (Ishimaru et al., 2010), Reln promoter in NT-2 neuronal precursor cells (Kundakovic et al., 2009), and restore recognition memory consolidation in ovariectomized mice (Zhao et al., 2010).

There are several limitations in the present study. First, there are multiple mechanisms during the sevoflurane related cognitive impairment, including neuroinflammation, metabolic alterations, electrophysiological changes, etc. DNA methylation variation and gene expressions could involve in these processes, and related investigations, including electrophysiology, should 
be performed in the future investigations. Second, as behavioral abnormal has multiple manifestations, combined behavior tests with Morris water maze, FCT and open field test should be performed in the future investigation to provide a comprehensive behavioral function during anesthesia and hippocampal DNA methylation modulation.

Taken together, sevoflurane anesthesia significantly reduced the expressions of $A r c, B d n f$ and Reln through inducing promoter hypermethylation in the hippocampus, which substantially contributed to cognitive impairment in aged rats. These impairments could be attenuated by 5-Aza pretreatment. Our study provides an epigenetic understanding for the pathophysiology of cognitive impairment induced by general anesthesia in the aged brain.

\section{DATA AVAILABILITY STATEMENT}

The datasets presented in this study can be found in online repositories. The names of the repository/repositories and accession number(s) can be found in the Dryad Digital Repository (https://doi.org/10.5061/dryad.69p8cz8xw).

\section{REFERENCES}

Aid, T., Kazantseva, A., Piirsoo, M., Palm, K., and Timmusk, T. (2007). Mouse and rat BDNF gene structure and expression revisited. J. Neurosci. Res. 85, 525-535. doi: $10.1002 /$ jnr.21139

Barter, J. D., and Foster, T. C. (2018). Aging in the brain: new roles of epigenetics in cognitive decline. Neuroscientist 24, 516-525. doi: 10.1177/1073858418780971

Bunting, K. M., Nalloor, R. I., and Vazdarjanova, A. (2015). Influence of Isoflurane on Immediate-Early Gene Expression. Front. Behav. Neurosci. 9:363. doi: 10. 3389/fnbeh.2015.00363

Carmichael, R. E., and Henley, J. M. (2018). Transcriptional and post-translational regulation of Arc in synaptic plasticity. Semin. Cell Dev. Biol. 77, 3-9. doi: 10.1016/j.semcdb.2017.09.007

Chapman, T. R., Barrientos, R. M., Ahrendsen, J. T., Hoover, J. M., Maier, S. F., and Patterson, S. L. (2012). Aging and infection reduce expression of specific brain-derived neurotrophic factor mRNAs in hippocampus. Neurobiol. Aging 33, 832.e831-814. doi: 10.1016/j.neurobiolaging.2011.07.015

Chastain-Potts, S. E., Tesic, V., Tat, Q. L., Cabrera, O. H., Quillinan, N., and Jevtovic-Todorovic, V. (2019). Sevoflurane Exposure Results in SexSpecific Transgenerational Upregulation of Target IEGs in the Subiculum. Mol. Neurobiol. 57, 11-22. doi: 10.1007/s12035-019-01752-0

Cheng, B., Zhang, Y., Wang, A., Dong, Y., and Xie, Z. (2015). Vitamin C attenuates isoflurane-induced caspase-3 activation and cognitive impairment. Mol. Neurobiol. 52, 1580-1589. doi: 10.1007/s12035-014-8959-3

Chowdhury, N., Quinn, J. J., and Fanselow, M. S. (2005). Dorsal hippocampus involvement in trace fear conditioning with long, but not short, trace intervals in mice. Behav. Neurosci. 119, 1396-1402. doi: 10.1037/0735-7044.119.5. 1396

Christman, J. K. (2002). 5-Azacytidine and 5-aza-2'-deoxycytidine as inhibitors of DNA methylation: mechanistic studies and their implications for cancer therapy. Oncogene 21, 5483-5495. doi: 10.1038/sj.onc. 1205699

Dalla Massara, L., Osuru, H. P., Oklopcic, A., Milanovic, D., Joksimovic, S. M., Caputo, V., et al. (2016). General Anesthesia Causes Epigenetic Histone Modulation of c-Fos and Brain-derived Neurotrophic Factor, Target Genes Important for Neuronal Development in the Immature Rat Hippocampus. Anesthesiology 124, 1311-1327. doi: 10.1097/aln.0000000000001111

Delgado-Morales, R., Agís-Balboa, R. C., Esteller, M., and Berdasco, M. (2017). Epigenetic mechanisms during ageing and neurogenesis as novel therapeutic avenues in human brain disorders. Clin. Epigenet. 9:67. doi: 10.1186/s13148017-0365-z

\section{ETHICS STATEMENT}

The animal study was reviewed and approved by the Peking University Biomedical Ethics Committee Experiment Animal Ethics Branch.

\section{AUTHOR CONTRIBUTIONS}

$\mathrm{CN}$ designed the project, performed the experiments, analyzed the data, and wrote and revised the manuscript. MQ wrote the original draft of the manuscript. JG, YT, and SL contributed to data analysis and manuscript revision. YQ and NY contributed to the experiments. HZ designed and supervised the project, and revised the manuscript. All authors read and approved the final manuscript.

\section{FUNDING}

This work was supported by the National Natural Science Foundation of China (Nos. 81771146, 81970994, and 81400869).

Doehner, J., and Knuesel, I. (2010). Reelin-mediated Signaling during Normal and Pathological Forms of Aging. Aging Dis. 1, 12-29.

Dong, X., and Li, Y. (2014). Peritraumatic startle response predicts the vulnerability to develop PTSD-like behaviors in rats: a model for peritraumatic dissociation. Front. Behav. Neurosci. 8:14. doi: 10.3389/fnbeh.2014.00014

Dong, Y., Zhang, G., Zhang, B., Moir, R. D., Xia, W., Marcantonio, E. R., et al. (2009). The common inhalational anesthetic sevoflurane induces apoptosis and increases beta-amyloid protein levels. Arch. Neurol. 66, 620-631. doi: 10.1001/ archneurol.2009.48

Duclot, F., and Kabbaj, M. (2017). The Role of Early Growth Response 1 (EGR1) in Brain Plasticity and Neuropsychiatric Disorders. Front. Behav. Neurosci. 11:35. doi: 10.3389/fnbeh.2017.00035

Dyrvig, M., Gotzsche, C. R., Woldbye, D. P., and Lichota, J. (2015). Epigenetic regulation of Dnmt3a and Arc gene expression after electroconvulsive stimulation in the rat. Mol. Cell Neurosci. 67, 137-143. doi: 10.1016/j.mcn.2015. 06.011

Ehrlich, M. (2019). DNA hypermethylation in disease: mechanisms and clinical relevance. Epigenetics 14, 1141-1163. doi: 10.1080/15592294.2019.1638701

Epstein, I., and Finkbeiner, S. (2018). The Arc of cognition: signaling cascades regulating Arc and implications for cognitive function and disease. Semin. Cell Dev. Biol. 77, 63-72. doi: 10.1016/j.semcdb.2017.09.023

Evered, L., Scott, D. A., and Silbert, B. (2017). Cognitive decline associated with anesthesia and surgery in the elderly: does this contribute to dementia prevalence? Curr. Opin. Psychiatry 30, 220-226. doi: 10.1097/yco. 0000000000000321

Evered, L., Silbert, B., Knopman, D. S., Scott, D. A., DeKosky, S. T., Rasmussen, L. S., et al. (2018). Recommendations for the Nomenclature of Cognitive Change Associated with Anaesthesia and Surgery-2018. Anesthesiology 129, 872-879. doi: 10.1097/aln.0000000000002334

Fasolino, M., and Zhou, Z. (2017). The Crucial Role of DNA Methylation and MeCP2 in Neuronal Function. Genes 8:141. doi: 10.3390/genes8050141

Feng, J., Zhou, Y., Campbell, S. L., Le, T., Li, E., Sweatt, J. D., et al. (2010). Dnmt1 and Dnmt3a maintain DNA methylation and regulate synaptic function in adult forebrain neurons. Nat. Neurosci. 13, 423-430. doi: 10.1038/nn.2514

Gao, X., Castro-Gomez, S., Grendel, J., Graf, S., Süsens, U., Binkle, L., et al. (2018). Arc/Arg3.1 mediates a critical period for spatial learning and hippocampal networks. Proc. Natl. Acad. Sci. U.S.A. 115, 12531-12536. doi: 10.1073/pnas. 1810125115

Halder, R., Hennion, M., Vidal, R. O., Shomroni, O., Rahman, R. U., Rajput, A., et al. (2016). DNA methylation changes in plasticity genes accompany 
the formation and maintenance of memory. Nat. Neurosci. 19, 102-110. doi: 10.1038/nn.4194

Haseneder, R., Starker, L., Berkmann, J., Kellermann, K., Jungwirth, B., Blobner, M., et al. (2013). Sevoflurane anesthesia improves cognitive performance in mice, but does not influence in vitro long-term potentation in hippocampus CA1 stratum radiatum. PLoS One 8:e64732. doi: 10.1371/journal.pone.00 64732

Hendrickx, A., Pierrot, N., Tasiaux, B., Schakman, O., Kienlen-Campard, P., De Smet, C., et al. (2014). Epigenetic regulations of immediate early genes expression involved in memory formation by the amyloid precursor protein of Alzheimer disease. PLoS One 9:e99467. doi: 10.1371/journal.pone.00 99467

Hsiao, Y. H., Hung, H. C., Yu, Y. J., Su, C. L., Chen, S. H., and Gean, P. W. (2017). Co-housing reverses memory decline by epigenetic regulation of brain-derived neurotrophic factor expression in an animal model of Alzheimer's disease. Neurobiol. Learn. Mem. 141, 1-8. doi: 10.1016/j.nlm.2017.02.020

Hwang, J. Y., Aromolaran, K. A., and Zukin, R. S. (2017). The emerging field of epigenetics in neurodegeneration and neuroprotection. Nat. Rev. Neurosci. 18, 347-361. doi: 10.1038/nrn.2017.46

Ishimaru, N., Fukuchi, M., Hirai, A., Chiba, Y., Tamura, T., Takahashi, N., et al. (2010). Differential epigenetic regulation of BDNF and NT-3 genes by trichostatin A and 5-aza-2' -deoxycytidine in Neuro-2a cells. Biochem. Biophys. Res. Commun. 394, 173-177. doi: 10.1016/j.bbrc.2010.02.139

Jevtovic-Todorovic, V., Absalom, A. R., Blomgren, K., Brambrink, A., Crosby, G., Culley, D. J., et al. (2013). Anaesthetic neurotoxicity and neuroplasticity: an expert group report and statement based on the BJA Salzburg Seminar. Br. J. Anaesth. 111, 143-151. doi: 10.1093/bja/aet177

Jia, M., Ji, M. H., and Yang, J. J. (2017). Epigenetic regulation of general anesthesiainduced neonatal neurodegeneration. Oncotarget 8, 5652-5653. doi: 10.18632/ oncotarget. 14568

Joksimovic, S. M., Osuru, H. P., Oklopcic, A., Beenhakker, M. P., JevtovicTodorovic, V., and Todorovic, S. M. (2018). Histone Deacetylase Inhibitor Entinostat (MS-275) Restores Anesthesia-induced Alteration of Inhibitory Synaptic Transmission in the Developing Rat Hippocampus. Mol. Neurobiol. 55, 222-228. doi: 10.1007/s12035-017-0735-8

Ju, L. S., Jia, M., Sun, J., Sun, X. R., Zhang, H., Ji, M. H., et al. (2016). Hypermethylation of Hippocampal Synaptic Plasticity-Related genes is Involved in Neonatal Sevoflurane Exposure-Induced Cognitive Impairments in Rats. Neurotox Res. 29, 243-255. doi: 10.1007/s12640-0159585-1

Knuesel, I., Nyffeler, M., Mormede, C., Muhia, M., Meyer, U., Pietropaolo, S., et al. (2009). Age-related accumulation of Reelin in amyloid-like deposits. Neurobiol. Aging 30, 697-716. doi: 10.1016/j.neurobiolaging.2007.08.011

Kundakovic, M., Chen, Y., Guidotti, A., and Grayson, D. R. (2009). The reelin and GAD67 promoters are activated by epigenetic drugs that facilitate the disruption of local repressor complexes. Mol. Pharmacol. 75, 342-354. doi: 10.1124/mol.108.051763

Lee, I., and Kesner, R. P. (2002). Differential contribution of NMDA receptors in hippocampal subregions to spatial working memory. Nat. Neurosci. 5, 162-168. doi: $10.1038 / \mathrm{nn} 790$

Levenson, J. M., Roth, T. L., Lubin, F. D., Miller, C. A., Huang, I. C., Desai, P., et al. (2006). Evidence that DNA (cytosine-5) methyltransferase regulates synaptic plasticity in the hippocampus. J. Biol. Chem. 281, 15763-15773. doi: 10.1074/jbc.M511767200

Li, X. Q., Cao, X. Z., Wang, J., Fang, B., Tan, W. F., and Ma, H. (2014). Sevoflurane preconditioning ameliorates neuronal deficits by inhibiting microglial MMP9 expression after spinal cord ischemia/reperfusion in rats. Mol. Brain 7:69. doi: 10.1186/s13041-014-0069-7

Liu, L., van Groen, T., Kadish, I., Li, Y., Wang, D., James, S. R., et al. (2011). Insufficient DNA methylation affects healthy aging and promotes agerelated health problems. Clin. Epigenet. 2, 349-360. doi: 10.1007/s13148-0110042-6

Liu, L., van Groen, T., Kadish, I., and Tollefsbol, T. O. (2009). DNA methylation impacts on learning and memory in aging. Neurobiol. Aging 30, 549-560. doi: 10.1016/j.neurobiolaging.2007.07.020

Lubin, F. D., Roth, T. L., and Sweatt, J. D. (2008). Epigenetic regulation of BDNF gene transcription in the consolidation of fear memory. J. Neurosci. 28, 10576-10586. doi: 10.1523/jneurosci.1786-08.2008
Maddocks, O. D., Labuschagne, C. F., Adams, P. D., and Vousden, K. H. (2016). Serine Metabolism Supports the Methionine Cycle and DNA/RNA Methylation through De Novo ATP Synthesis in Cancer Cells. Mol. Cell 61, 210-221. doi: 10.1016/j.molcel.2015.12.014

Miller, C. A., Gavin, C. F., White, J. A., Parrish, R. R., Honasoge, A., Yancey, C. R., et al. (2010). Cortical DNA methylation maintains remote memory. Nat. Neurosci. 13, 664-666. doi: 10.1038/nn.2560

Mitchell, C. P., Chen, Y., Kundakovic, M., Costa, E., and Grayson, D. R. (2005). Histone deacetylase inhibitors decrease reelin promoter methylation in vitro. J. Neurochem. 93, 483-492. doi: 10.1111/j.1471-4159.2005.03040.x

Moller, J. T., Cluitmans, P., Rasmussen, L. S., Houx, P., Rasmussen, H., Canet, J., et al. (1998). Long-term postoperative cognitive dysfunction in the elderly ISPOCD1 study. ISPOCD investigators. International Study of Post-Operative Cognitive Dysfunction. Lancet 351, 857-861. doi: 10.1016/s0140-6736(97) 07382-0

Monk, T. G., Weldon, B. C., Garvan, C. W., Dede, D. E., van der Aa, M. T., Heilman, K. M., et al. (2008). Predictors of cognitive dysfunction after major noncardiac surgery. Anesthesiology 108, 18-30. doi: 10.1097/01.anes. $0000296071.19434 .1 \mathrm{e}$

Nan, X., Campoy, F. J., and Bird, A. (1997). MeCP2 is a transcriptional repressor with abundant binding sites in genomic chromatin. Cell 88, 471-481. doi: 10.1016/s0092-8674(00)81887-5

Navada, S. C., Steinmann, J., Lübbert, M., and Silverman, L. R. (2014). Clinical development of demethylating agents in hematology. J. Clin. Invest. 124, 40-46. doi: $10.1172 /$ jci69739

Ni, C., Li, C., Dong, Y., Guo, X., Zhang, Y., and Xie, Z. (2017). Anesthetic Isoflurane Induces DNA Damage Through Oxidative Stress and p53 Pathway. Mol. Neurobiol. 54, 3591-3605. doi: 10.1007/s12035-0169937-8

Ni, C., Li, Z., Qian, M., Zhou, Y., Wang, J., and Guo, X. (2015). Isoflurane induced cognitive impairment in aged rats through hippocampal calcineurin/NFAT signaling. Biochem. Biophys. Res. Commun. 460, 889-895. doi: 10.1016/j.bbrc. 2015.03 .083

Nonaka, M., Kim, R., Sharry, S., Matsushima, A., Takemoto-Kimura, S., and Bito, H. (2014). Towards a better understanding of cognitive behaviors regulated by gene expression downstream of activity-dependent transcription factors. Neurobiol. Learn. Mem. 115, 21-29. doi: 10.1016/j.nlm.2014.08.010

Okano, M., Bell, D. W., Haber, D. A., and Li, E. (1999). DNA methyltransferases Dnmt3a and Dnmt3b are essential for de novo methylation and mammalian development. Cell 99, 247-257. doi: 10.1016/s0092-8674(00)81 656-6

Palomer, E., Carretero, J., Benvegnù, S., Dotti, C. G., and Martin, M. G. (2016a). Neuronal activity controls Bdnf expression via Polycomb de-repression and CREB/CBP/JMJD3 activation in mature neurons. Nat. Commun. 7:11081. doi: 10.1038/ncomms11081

Palomer, E., Martín-Segura, A., Baliyan, S., Ahmed, T., Balschun, D., Venero, C., et al. (2016b). Aging Triggers a Repressive Chromatin State at Bdnf Promoters in Hippocampal Neurons. Cell Rep. 16, 2889-2900. doi: 10.1016/j.celrep.2016. 08.028

Penner, M. R., Roth, T. L., Chawla, M. K., Hoang, L. T., Roth, E. D., Lubin, F. D., et al. (2011). Age-related changes in Arc transcription and DNA methylation within the hippocampus. Neurobiol. Aging 32, 2198-2210. doi: 10.1016/j. neurobiolaging.2010.01.009

Pujadas, L., Rossi, D., Andrés, R., Teixeira, C. M., Serra-Vidal, B., Parcerisas, A., et al. (2014). Reelin delays amyloid-beta fibril formation and rescues cognitive deficits in a model of Alzheimer's disease. Nat. Commun. 5:3443. doi: 10.1038/ ncomms 4443

Robertson, K. D., Uzvolgyi, E., Liang, G., Talmadge, C., Sumegi, J., Gonzales, F. A., et al. (1999). The human DNA methyltransferases (DNMTs) 1, 3a and 3b: coordinate mRNA expression in normal tissues and overexpression in tumors. Nucleic Acids Res. 27, 2291-2298. doi: 10.1093/nar/27.11.2291

Sachser, R. M., Santana, F., Crestani, A. P., Lunardi, P., Pedraza, L. K., Quillfeldt, J. A., et al. (2016). Forgetting of long-term memory requires activation of NMDA receptors, L-type voltage-dependent Ca2+ channels, and calcineurin. Sci. Rep. 6:22771. doi: 10.1038/srep22771

Schulte, P. J., Roberts, R. O., Knopman, D. S., Petersen, R. C., Hanson, A. C., Schroeder, D. R., et al. (2018). Association between exposure to anaesthesia and surgery and long-term cognitive trajectories in older adults: report from the 
Mayo Clinic Study of Aging. Br. J. Anaesth. 121, 398-405. doi: 10.1016/j.bja. 2018.05.060

Semick, S. A., Bharadwaj, R. A., Collado-Torres, L., Tao, R., Shin, J. H., Deep-Soboslay, A., et al. (2019). Integrated DNA methylation and gene expression profiling across multiple brain regions implicate novel genes in Alzheimer's disease. Acta Neuropathol. 137, 557-569. doi: 10.1007/s00401-01901966-5

Singh, P., Konar, A., Kumar, A., Srivas, S., and Thakur, M. K. (2015). Hippocampal chromatin-modifying enzymes are pivotal for scopolamine-induced synaptic plasticity gene expression changes and memory impairment. J. Neurochem. 134, 642-651. doi: 10.1111/jnc.13171

Stranahan, A. M., Erion, J. R., and Wosiski-Kuhn, M. (2013). Reelin signaling in development, maintenance, and plasticity of neural networks. Ageing Res. Rev. 12, 815-822. doi: 10.1016/j.arr.2013.01.005

Sun, Z., Xu, X., He, J., Murray, A., Sun, M. A., Wei, X., et al. (2019). EGR1 recruits TET1 to shape the brain methylome during development and upon neuronal activity. Nat. Commun. 10:3892. doi: 10.1038/s41467-019-11905-3

Tan, W., Zhu, Z., Ye, L., and Leung, L. K. (2017). Methylation dictates PI.f-specific CYP19 transcription in human glial cells. Mol. Cell Endocrinol. 452, 131-137. doi: 10.1016/j.mce.2017.05.029

Telese, F., Ma, Q., Perez, P. M., Notani, D., Oh, S., Li, W., et al. (2015). LRP8-ReelinRegulated Neuronal Enhancer Signature Underlying Learning and Memory Formation. Neuron 86, 696-710. doi: 10.1016/j.neuron.2015.03.033

Teroganova, N., Girshkin, L., Suter, C. M., and Green, M. J. (2016). DNA methylation in peripheral tissue of schizophrenia and bipolar disorder: a systematic review. BMC Genet. 17:27. doi: 10.1186/s12863-016-0332-2

Williams-Karnesky, R. L., Sandau, U. S., Lusardi, T. A., Lytle, N. K., Farrell, J. M., Pritchard, E. M., et al. (2013). Epigenetic changes induced by adenosine augmentation therapy prevent epileptogenesis. J. Clin. Invest. 123, 3552-3563. doi: 10.1172/JCI65636

Wu, J., Bie, B., and Naguib, M. (2016). Epigenetic Manipulation of Brainderived Neurotrophic Factor Improves Memory Deficiency Induced by Neonatal Anesthesia in Rats. Anesthesiology 124, 624-640. doi: 10.1097/aln. 0000000000000981

Zhao, Z., Fan, L., and Frick, K. M. (2010). Epigenetic alterations regulate estradiolinduced enhancement of memory consolidation. Proc. Natl. Acad. Sci. U.S.A. 107, 5605-5610. doi: 10.1073/pnas.0910578107

Zhu, H., Wang, G., and Qian, J. (2016). Transcription factors as readers and effectors of DNA methylation. Nat. Rev. Genet. 17, 551-565. doi: 10.1038/nrg. 2016.83

Zhubi, A., Chen, Y., Dong, E., Cook, E. H., Guidotti, A., and Grayson, D. R. (2014). Increased binding of MeCP2 to the GAD1 and RELN promoters may be mediated by an enrichment of 5-hmC in autism spectrum disorder (ASD) cerebellum. Transl. Psychiatry 4:e349. doi: 10.1038/tp.2013.123

Conflict of Interest: The authors declare that the research was conducted in the absence of any commercial or financial relationships that could be construed as a potential conflict of interest.

Copyright (c) $2020 \mathrm{Ni}$, Qian, Geng, Qu, Tian, Yang, Li and Zheng. This is an openaccess article distributed under the terms of the Creative Commons Attribution License (CC BY). The use, distribution or reproduction in other forums is permitted, provided the original author(s) and the copyright owner(s) are credited and that the original publication in this journal is cited, in accordance with accepted academic practice. No use, distribution or reproduction is permitted which does not comply with these terms. 